\title{
Fabrication, Doping and Characterization of Polyaniline and Metal Oxides: Dye Sensitized Solar Cells
}

\author{
Sadia Ameen ${ }^{1}$, M. Shaheer Akhtar², \\ Young Soon $\mathrm{Kim}^{1}$ and Hyung-Shik Shin ${ }^{1}$ \\ ${ }^{1}$ Energy Materials \& Surface Science Laboratory, Solar Energy Research Center, \\ School of Chemical Engineering, Chonbuk National University, Jeonju, \\ ${ }^{2}$ New \& Renewable Energy Material Development Center (NewREC), \\ Chonbuk National University, Jeonbuk, \\ Republic of Korea
}

\section{Introduction}

The photoelectrochemical devices like dye sensitized solar cell (DSSCs) are the promising photovoltaic device for the utilization of solar into electricity energy by converting solar radiation through the generation of photogenerated carriers. DSSCs possess the benign properties of low cost, high conversion efficiency and ease of fabrication (Gratzel, 2005, 2004 \& Frank, et al., 2004). Several significant advantages are associated to DSSCs such as the semiconductor-electrolyte interface (SEI) is easy to manufacture and it is cost effective for production, non sensitive to the defects, the two functions of light harvesting and chargecarrier transport are remain separated and favours the direct energy transfer from photons to chemical energy. Although, DSSCs are the promising photovoltaic technology for achieving reasonably high conversion efficiency but the improvements are still demanded to develop a high potential technology.

A typical DSSC is comprised of a dye-coated mesoporous nanocrystalline metal oxide semiconductor, machinated between two the conductive transparent electrodes as shown in Fig. 1. A liquid iodide/tri-iodide redox couple as an electrolyte is introduced to fill the pores of the film and to improve the contact between the nanoparticles (Gratzel, 2000). Upon photo excitation of the dye, the electrons are injected into the conduction band of the nanocrystalline metal oxide semiconductor and the original state of the dye is restored by the electron donation from the hole conductor. The regeneration of the sensitizer by the hole conductor intercepts the recapture of the conduction band electron by the oxidized dye and the hole conductor is regenerated at the counter-electrode. The circuit is completed via electron migration through the external load.

Nanocrystalline metal oxide semiconductor like $\mathrm{TiO}_{2}, \mathrm{ZnO}$ and $\mathrm{SnO}_{2}$ etc have been accepted as the effective photoanode materials for DSSCs due to their good optical and electronic properties. Till date, DSSCs constructed from $\mathrm{TiO}_{2}$ nanocrystalline metal oxide electrodes has presented the highest solar to electricity conversion efficiency of $11.4 \%$. These nanocrystalline metal oxide semiconductors possess high surface to volume ratio required 


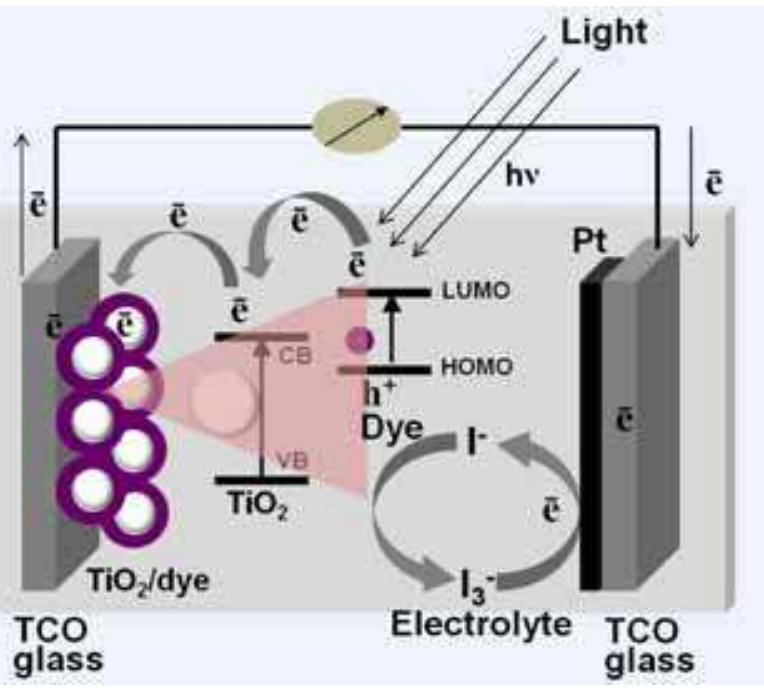

Fig. 1. Mechanistic diagram of dye sensitized solar cell under light illumination.

for the high absorption of dye molecules for the improved light harvesting efficiency but the challenges like enhancement in the electron transport rate, reduction of recombination rate and the improvement in the energy conversion efficiency are still associated with metal oxide semiconductor based DSSCs. It has been reported that the photoelectrodes made of metal oxides nanostructures like nanoparticles, nanorods, nanowires and nanotubes improve the photovoltaic properties of DSSCs such as $\mathrm{JSC}_{\mathrm{S}}, \mathrm{V}_{\mathrm{OC}}, \mathrm{FF}$ and conversion efficiency by the effective electron transfer during the performance of DSSCs. The conducting polymers are the semiconducting polymers which exhibit good electrical properties similar to metals and possess unique properties like light weight, resistance to corrosion, flexibility and low cost. The nanostructures of conducting polymers are excessively exploited in the electronic devices due to the large surface area of the nanomaterials and their unique electronic properties (Huang et al., 2006, Zhnag et al., 2006, Wan, 2008, 2009 \& Li et al., 2009). These perspectives have prompted the researchers for the rapid development of conducting polymers and the nanocrystalline metal oxide semiconductors for improving the processability, functionality and the conversion efficiency of DSSCs.

In this chapter, we have briefly surveyed the conducting polymers, its doping and the different morphologies of nanocrystalline metal oxide semiconductors for the effective processing, functionality and the fabrication of DSSCs. The chapter focuses the recent developments in the heterostructures diodes, Ohmic devices and DSSCs fabricated with polyaniline (PANI) and the nanostructured metal oxides. The morphology, structure and physiochemical properties of $\mathrm{TiO}_{2}$ and $\mathrm{ZnO}$ nanostructure semiconductors have been reviewed as photoelectrode for the application of DSSCs. It has been reviewed that the performances of DSSCs are considerably affected by the preparation, morphology and the electrical properties of conducting polymers and metal oxide semiconductors. $\mathrm{TiO}_{2}$ and $\mathrm{ZnO}$ nanostructures based photoelectrodes have shown comparable photovoltaic performance compared to the conventional $\mathrm{TiO}_{2}$ nanoparticles based DSSCs. On the other hand, the conducting polymers as a hole transport materials are found as the potential candidates for 
replacing the liquid electrolyte in DSSCs and the dopants have been discussed for enhancing the conducting properties of a particular polymer i.e. PANI.

\section{Aspects of conducting polymers}

The polymers are insulators due to the covalent bonded atoms in the polymer chain and thus, there is no scope for the delocalization of the valence electrons and consequently neither charge carriers nor the path for their movement are available (Stejskal et al., 2002). However, the important classes of polymers called as conducting polymers are semiconductors (Friend et al., 1999) and their band gaps could be tuned by alternating the chemical nature of either the polymer backbone or the side groups present in the polymeric chain. The overlapping of the molecular orbital for the formation of the delocalized molecular wave functions and secondly the partially filled molecular orbital for a free movement of electrons throughout the polymeric structure are the basic requirements for the polymers to become conducting in nature. These conducting polymers exhibit the unusual electronic properties such as electrical conductivity, low energy optical transitions, low ionization potential and high electron affinity (Park et al., 2010) due to the presence of extended п-conjugated systems along the polymeric chain (Gerard et al., 2002). The electrical properties of the conducting polymers could be easily tuned from insulating to metallic range by the reversible chemical, electrochemical and physical properties controlled by a doping/de-doping procedure. The electrical properties are changed by the partial oxidation or reduction of the polymer chain during the doping procedure. The conducting polymers possess the appended advantage of tailor-made property for accomplishing the requirements of the particular application through the modifications in the polymer structure. It is reported that the nanostructures of conducting polymer not only retain these unique characteristics, but also exhibit the properties like large surface area, size, and quantum effect etc which are important for designing and making the novel photovoltaic devices (Xia et al., 2010). Out of several conducting polymers, polyaniline (PANI) is the centre of scientific interest and has been considered as one of the most potential conducting polymers. The interest in PANI could possibly be linked to the numerous applications for various electrochemical, electro rheological and in the electronic fields such as batteries, sensors, controlling systems and organic displays (Smith, 1998, Wessling, 2001, Cho et al., 2002 \& Choi et al. 2001) because of its facile synthetic process, good environmental stability, easy conductivity control and cheap production in large quantities. The high yield of PANI demands several essential conditions such as highly pured monomers, chemicals and solvents for obtaining the high quality polymer, the strict control on the polymerization conditions, inert and dry environment for the polymerization since the small variation in the polymerization conditions might alter the nature of the product, and as PANI might undergo isomerization reaction under light and heat therefore, the synthesized PANI products should be kept in a dark, cool and dry place (Ameen, et al., 2010)

\section{General approaches for the synthesis of PANI}

\subsection{Interfacial polymerization}

In a typical reaction (Huang, et al., 2003, Virji, et al., 2004, King, et al., 2005 \& Huang et al., 2004) aniline monomer is dissolved into the organic solvents which have either low or high density than water like hexane, benzene, toluene, carbon tetrachloride, chloroform etc. A 
separate aqueous solution of ammonium peroxydisulphate (APS) as an oxidant is prepared with the acids such as $\mathrm{HCl}$, sulfuric acid, CSA, toluene sulfonic acid etc. The two solutions are then gently transferred to a glass vial for the generating the interface between the two layers. As the reaction proceeds, the green colored PANI is formed at the interface and gradually migrates into the aqueous phase and slowly the entire aqueous phase get filled homogeneously with dark-green PANI. The aqueous phase is collected through filtration after $24 \mathrm{~h}$. The non-conducting PANI could be obtained by dialyzing the synthesized PANI with ammonia solution

\subsection{Rapid mixing of reactants}

This is the simplest method for synthesizing PANI and in place of conventionally slow addition of the aqueous APS solution, the aniline monomer is mixed rapidly with APS solution. Here, the initiator molecules are consumed rapidly after the initialization of the polymerization reaction due to the even distribution of aniline monomer and APS molecules in the solution.

\subsection{Sonochemical synthesis}

Jing et al (Jing, et al., 2006, 2007) has reported the synthesis of PANI similar to the synthesis procedure of conventional PANI. The acidic APS solution is added dropwise to an acidic aniline solution, and subjected to the ultrasonic irradiation which results to the high yield of PANI. It has been found that the excessive addition of aniline monomer or APS could contribute to the continuous formation of the primary PANI products or could lead the agglomeration of PANI. Unlike conventional procedure where irregular morphology of PANI is obtained, the sonochemical synthesis strictly prevents the further growth and agglomeration and thus, generates uniform morphology of PANI.

\subsection{Electrophoretic synthesis}

The first step of a reaction requires a preparation of conducting PANI through the chemical procedure using APS as oxidant. In the second step, a stock solution of PANI $(1 \mathrm{mg} / \mathrm{ml})$ is prepared in the formic acid and the colloidal suspension is prepared by adding $100 \mathrm{ml}$ of the stock solution into acetonitrile for the preparation of an electrolyte. In the colloidal suspension, PANI dissociate into ions due to high dielectric medium which is offered by acetonitrile and thus, results to the formation of the positively charged PANI. The last step involves the electrophoretic film deposition where under the influence of applied voltage for a required time duration, positively charged colloid spheres of PANI in acidic colloidal suspension starts moving towards the negatively biased fluorinated tin oxide glass (FTO) electrode. This stepwise growth synthesis produces the uniform nanostructures of PANI on the surfaces of the FTO glass substrates.

\subsection{Plasma polymerization}

The plasma polymerization, as shown in Fig. 2 requires four parts (1) a reactor chamber quartz tube (2 cm), (2) Cu coil (4 in.), (3) plasma system (R.F. generator: 0-600 W, matching network frequency of $13.56 \mathrm{MHz}$ ) and (4) mechanical vacuum pump (speed $6001 / \mathrm{min}$ ). The glow discharges are introduced through RF amplifier with a resistive coupling mechanism at $13.5 \mathrm{MHz}$ and power of $120 \mathrm{~W}$. These discharges are set without carrier gas or any other additional chemical elements to prevent the contamination. The cleaned FTO glass 
substrates are placed just below the RF coil, placed inside the quartz tube. Initially, the chamber is evacuated to a base pressure of $10^{-3}$ Torr through a rotator vacuum pump. After attaining the base pressure, aniline monomer is injected, using a hypodermic syringe and the reaction is promoted by the collisions of the aniline monomer molecules with the ions/particles present in the plasma.

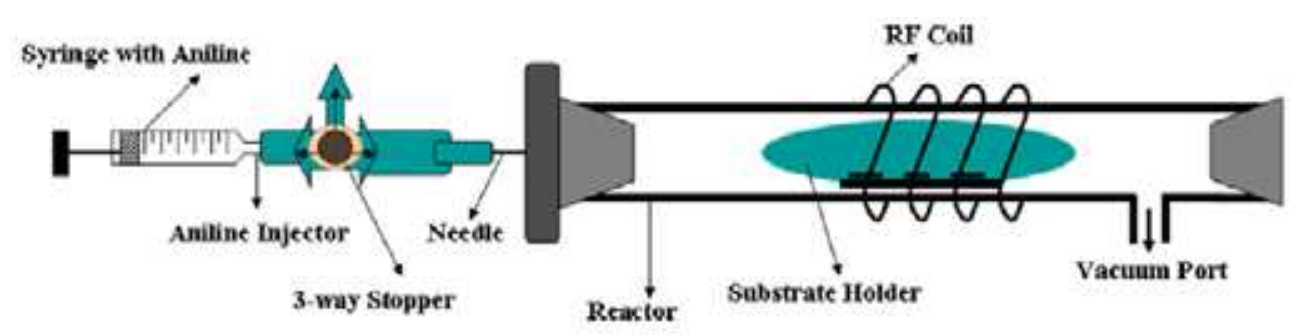

Fig. 2. Reactor setup for plasma synthesis of PANI. Reprinted with permission from [Ameen S. et al 2009], Superlatt. Microstruc. 46 (2009) 745. (C) 2009, Elsevier Ltd.

\section{Concept of doping in PANI}

Doping is the unique, central, underlying and unifying concept, which distinguishes PANI as conducting polymer from other insulating polymers. The controlled addition of known chemical species results in the dramatic changes in the electronic, electrical, magnetic, optical and structural properties of PANI. The doping procedures of inorganic semiconductors and for conducting polymers including PANI are fundamentally different from each other. In PANI, the dopant concentrations are exceptionally high compared to commonly doped inorganic semiconductors (typically in parts per million ranges) and the doping of PANI involves random dispersion or aggregation of dopants in molar concentrations in the disordered structure of entangled chains and fibrils. However, for inorganic semiconductors, the doping generates either holes in the valence band or electrons in the conduction band. The doping of PANI generates high conductivity primarily by increasing the carrier concentrations and leads to the conjugational defect like solitons, polarons, bipolarons in the polymer chain. Doping is a reversible produce which could be carried out chemically or electrochemically with the oxidation or reduction by accepting or donating the electrons respectively and thus, results to the positive or negative charges. Ameen et al have used various acids and binary mixtures as dopants to improve the electrical conductivity of PANI.

\subsection{Doping with sulfamic acid}

Sulfamic acid is one of the promising dopant which displays the properties of handling ease, solubility, and low corrosiveness. It is a dry, non-volatile stable solid acid, which is moderately soluble in water at room temperature. Wadia et al prepared the thin film of sulfamic acid doped PANI as electrochemical sensor for the determination of nitrite (Dhaoui, et al., 2007, 2008). Ameen et al reported the electrical conductivity of PANI nanostructures in the range of $1.1 \times 10^{-4}-4.50 \times 10^{-3} \mathrm{ohm}^{-1} \mathrm{~cm}^{-1}$, doped with different $\mathrm{wt} \%$ of sulfamic acid (Ameen, et al., 2007). Moreover, PANI nanofibers doped with sulfamic acid thin film was applied as counter electrodes for the fabrication of DSSCs and obtained the conductivity of $2.06 \times 10^{-4} \mathrm{ohm}^{-1} \mathrm{~cm}^{-1}$ by Ameen et al (Ameen, et al., 2010). 


\subsection{Doping with sodium thiosulphate}

Sodium thiosulphate is an odorless translucent crystals or white crystalline powder which is soluble in water and exhibit the stability. It is incompatible with strong acid and is not hazardous. Ameen et al reported the electrical conductivity of PANI nanostructures in the range of $8.55 \times 10^{-9}-3.67 \times 10^{-7} \mathrm{ohm}^{-1} \mathrm{~cm}^{-1}$ after doping with sodium thiosulphate (Ameen, et al., 2009).

\subsection{Doping with samarium (III) chloride}

Samarium (III) chloride is a light yellow colored strong Lewis acid. This dopant is non hazardous and stable in nature and is reported to increase the conductivity of PANI nanostructure from $3.70 \times 10^{-11}$ to $1.30 \times 10^{-9} \mathrm{ohm}^{-1} \mathrm{~cm}^{-1}$ (Ameen, et al., 2009).

\subsection{Doping with praseodymium (III) chloride}

Praseodymium (III) Chloride is a green colored powder which does not show thermal decomposition and is stable in nature. It is an excellent water-soluble crystalline strong Lewis acid and after doping is reported to show the conductivity of PANI nanostructures in the range $1.87 \times 10^{-11}-2.22 \times 10^{-10} \mathrm{ohm}^{-1} \mathrm{~cm}^{-1}$ (Ameen, et al., 2008).

\subsection{Doping with binary dopant: $\mathrm{ZrO}_{2} / \mathrm{Agl} \& \mathrm{ZrO}_{2} / \mathrm{Pbl}_{2}$}

In this binary dopant mixture $\mathrm{ZrO}_{2}$ is a luminescent material which usually makes no contribution in the conductivity of PANI. On the other hand, AgI is a non luminescent material which enhances the conductivity of PANI. The binary effects of these two materials have improved the optical and the electrical conductivity of PANI nanostructures in the range of $9.28 \times 10^{-10}-3.763 \times 10^{-6} \mathrm{ohm}^{-1} \mathrm{~cm}^{-1}$ (Ameen, et al., 2007). Shaoxu et al reported the synthesis, characterization and the thermal analysis of PANI- $\mathrm{ZrO}_{2}$ nanocomposites (Wang, et al., 2006). The increased $\mathrm{ZrO}_{2}$ concentration in the binary dopant mixture exhibits a high PL emission intensity which improves optoelectronic properties of PANI. Ameen et al reported the effect of $\mathrm{ZrO}_{2} / \mathrm{PbI}_{2}$ doping on the electrical properties of PANI and the conductivity improves from $2.70 \times 10^{-13}$ to $8.81 \times 10^{-4} \mathrm{ohm}^{-1} \mathrm{~cm}^{-1}$ (Ameen, et al., 2009).

\section{Applications of PANI in heterostructure devices}

\subsection{Electrophoretic deposition of PANI for heterostructure devices 5.1.1 Electrophoretically deposited PANI/ZnO heterostructure diodes}

The fabrication of inorganic/organic heterostructure diodes is reported by the electrophoretic process for depositing organic materials (PANI, p-type) film on inorganic ntype $\mathrm{ZnO}$ NPs thin film substrate with top Pt thin layer contact by Ameen et al (Ameen, et al., 2009). The pristine $\mathrm{ZnO}$ film is composed of well crystalline $\mathrm{ZnO}$ nanoparticles of size $\sim 50-70 \mathrm{~nm}$, shown in Fig. 3 (a). The penetration of the PANI molecules into the crystalline $\mathrm{ZnO}$ NPs thin film upon electrophoretic deposition display the accumulation of ZnO NPs and thus, the size of $\mathrm{ZnO}$ nanoparticles get increased to $\sim 90 \mathrm{~nm}$ (Fig. 3 (b)). This assemblage confirms the substantive interaction and incorporation of electrophoretic deposited PANI into the crystalline $\mathrm{ZnO}$ nanoparticles thin film substrates.

The FTIR studies (Fig. 4 (I)) shows the considerable shifting of the peaks might due to the bonding between the hydroxyl groups and the imine groups of the PANI molecules. Noticeably, the UV-visible spectra of PANI/ZnO thin film (Fig. 4 (II)) shows that the peak (a) retains its position, considerable large blue shift for peak (b) is noticed and small red shift 


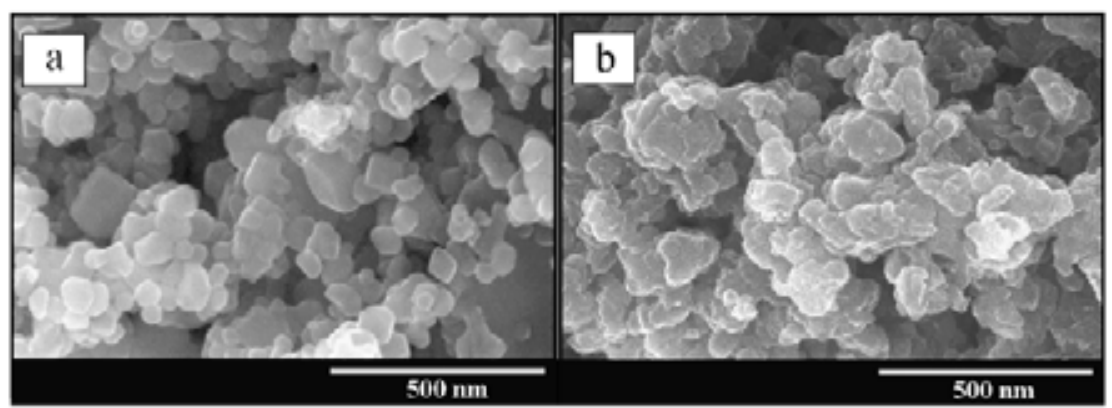

Fig. 3. Surface FE-SEM images of (a) synthesized ZnO nanoparticles (b) electrophoretically deposited PANI/ZnO thin film. Reprinted with permission from [Ameen S. et al, 2009], Superlatt. Microstruc. 46 (2009) 872. (C) 2009, Elsevier Ltd.
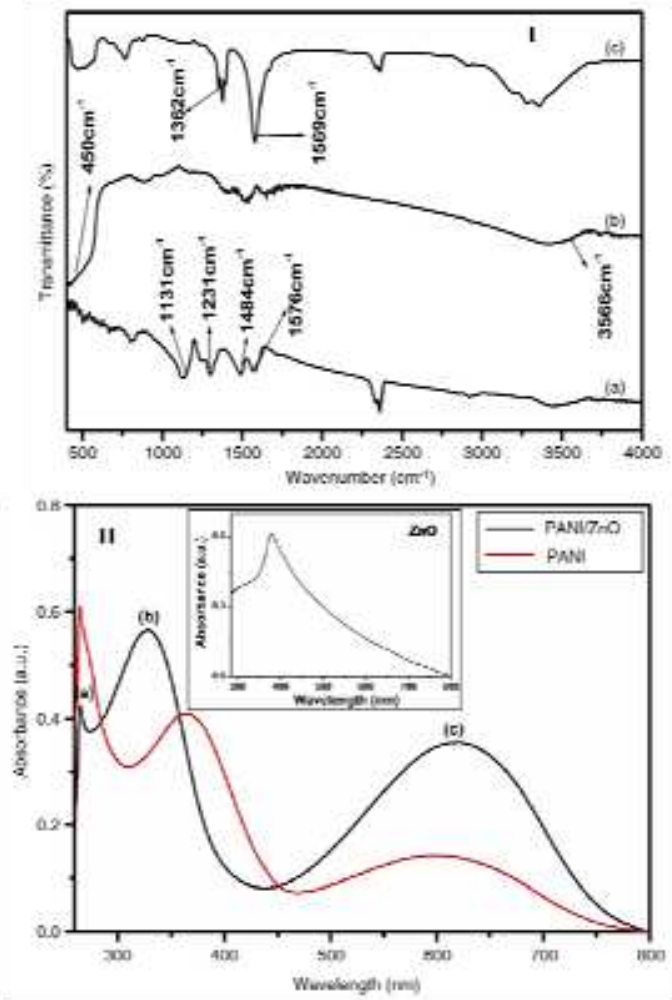

Fig. 4. (I): Typical FTIR spectrum of (a) pristine PANI (b) ZnO nanoparticles and (c) electrophoretically deposited PANI/ZnO thin film. (II): UV-Vis spectra of pristine PANI and electrophoretically deposited PANI/ZnO thin film. Inset shows the UV-Vis spectrum of $\mathrm{ZnO}$ nanoparticles. Reprinted with permission from [Ameen S., 2009], Superlatt. Microstruc. 46 (2009) 872. (c) 2009, Elsevier Ltd. 
in peak (c) are noticed after the deposition of PANI and thus, ascribed to the selective interactions between $\mathrm{ZnO}$ and the quinoid ring of ES which facilitates the charge transfer from quinoid unit of $\mathrm{ES}$ to $\mathrm{ZnO}$ via highly reactive imine group. This interaction between $\mathrm{ZnO}$ and PANI contributes to the decrease in the degree of orbital overlap between the $\pi$ electrons of the phenyl rings with the lone pair of the nitrogen atom in the PANI molecules and found to form a strong hydrogen bonding. Consequently, the extent of conjugation of PANI decreases, thus resulting in the increased intensity of the peak in PANI/ZnO thin film substrate and conclusively, the absorption of PANI/ZnO thin film increases over the whole range of visible light.

The I-V characteristics exhibit almost the symmetrical behavior both in the reverse and the forward bias and the current increases linearly with the increased applied voltage. The ohmic behavior is due to the formation of ohmic contacts at the interfaces of PANI and ZnO layers. Additionally, the presence of PANI minimizes the width of the depletion layer at the interface of $\mathrm{ZnO}$ nanoparticles and thus contributes to the typical ohmic system. The PANI/ZnO heterostructure reveals that the forward bias current increases by a factor two with an increase in the applied voltage. It is attributed that the formation of polarons and bipolarons in PANI increases rapidly and ultimately, contributes to the higher current in PANI at the high applied voltage. A schematic diagram and I-V characteristics of PANI/ZnO p-n heterostructure diode is shown in Fig. 5 (a).

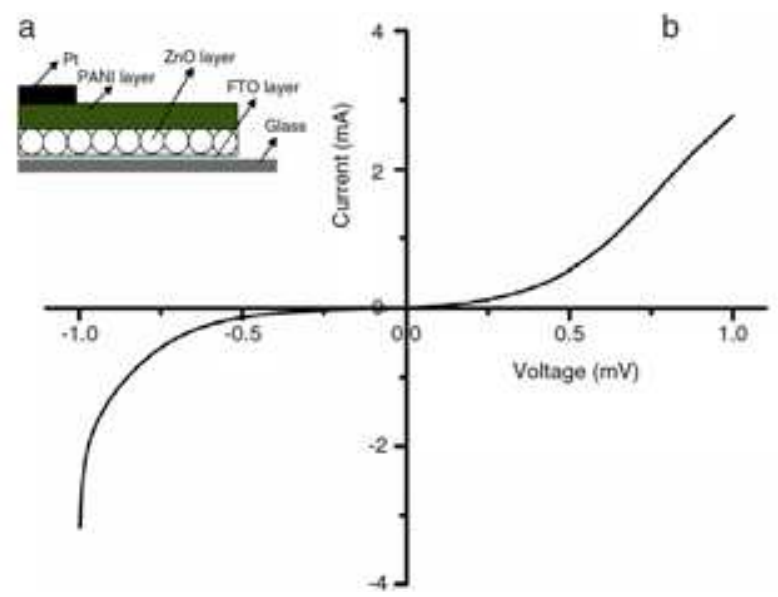

Fig. 5. (a) A schematic representation and (b) I-V characteristics of p-n heterostructure diode of Pt/PANI/ZnO. Reprinted with permission from [Ameen S., 2009], Superlatt. Microstruc. 46 (2009) 872. (c) 2009, Elsevier Ltd.

Current-voltage (I-V) measurements of PANI/ZnO heterostructure was carried out at $298 \mathrm{~K}$ with an applied voltage ranges from $-1 \mathrm{~V}$ to $+1 \mathrm{~V}$. The obtained $\mathrm{I}-\mathrm{V}$ characteristics exhibit weak rectifying with the non-linear nature of $\mathrm{Pt} / \mathrm{PANI} / \mathrm{ZnO}$ heterostructure diode where $\mathrm{Pt}$ thin layer might form a Schottky contact with PANI/ZnO layer as shown in Fig. 5 (b). The $\mathrm{Pt}$ layer on PANI/ZnO heterostructure might have originated a barrier between the interfaces of PANI/ZnO layer and Pt layer, and is responsible for the non-linear nature of I$\mathrm{V}$ characteristics. The $\mathrm{Pt} / \mathrm{PANI} / \mathrm{ZnO}$ heterostructure diode displays the rectification ratio $\left(\mathrm{I}_{\mathrm{f}} / \mathrm{I}_{\mathrm{r}}\right)$ of $\sim 4.2$ which is obtained from the forward $\left(\mathrm{I}_{\mathrm{f}}\right)$ and reverse $\left(\mathrm{I}_{\mathrm{r}}\right)$ current at $0.5 \mathrm{~V}$. This 
low $\mathrm{I}_{\mathrm{f}} / \mathrm{I}_{\mathrm{r}}$ value indicates that the PANI/ZnO heterostructure exhibits a weak rectifying nature and attains low turn-on voltage of $\sim 0.15 \mathrm{~V}$ and delivers reasonably high current of $\sim 0.08 \mathrm{~mA}$ with broader breakdown voltage $(\sim 0.52 \mathrm{~V})$ with very high leakage current of $\sim 0.6$ $\mathrm{mA}$.

\subsubsection{Electrophoretically deposited $\mathrm{PANI} / \mathrm{TiO}_{2}$ heterostructure diodes}

PANI has been electrophoretically deposited (EPD) on the surface of $\mathrm{TiO}_{2}$ nanoparticulate thin film for the fabrication of heterostructure devices by Ameen et al (Ameen, et al., 2011). The enhancements in the electron transport and current density have been explained in terms of the increased charge carriers mobility with improved optical absorption by the heterostucture diodes. Fig. 6 (a) shows the morphology of well crystalline $\mathrm{TiO}_{2}$ nanoparticles thin film of size $\sim 20-25 \mathrm{~nm}$. However, upon EPD, the size of $\mathrm{TiO}_{2}$ nanoparticles increased to $\sim 70-80 \mathrm{~nm}$ (Fig. 6 (b)) might due to the penetration of PANI molecules into the pores of mesoporous $\mathrm{TiO}_{2}$ nanoparticulate thin film. Additionally, the uniform deposition and the penetration of $\mathrm{PANI}$ on $\mathrm{TiO}_{2}$ nanoparticulate thin film could be seen in the Fig. 6 (c).
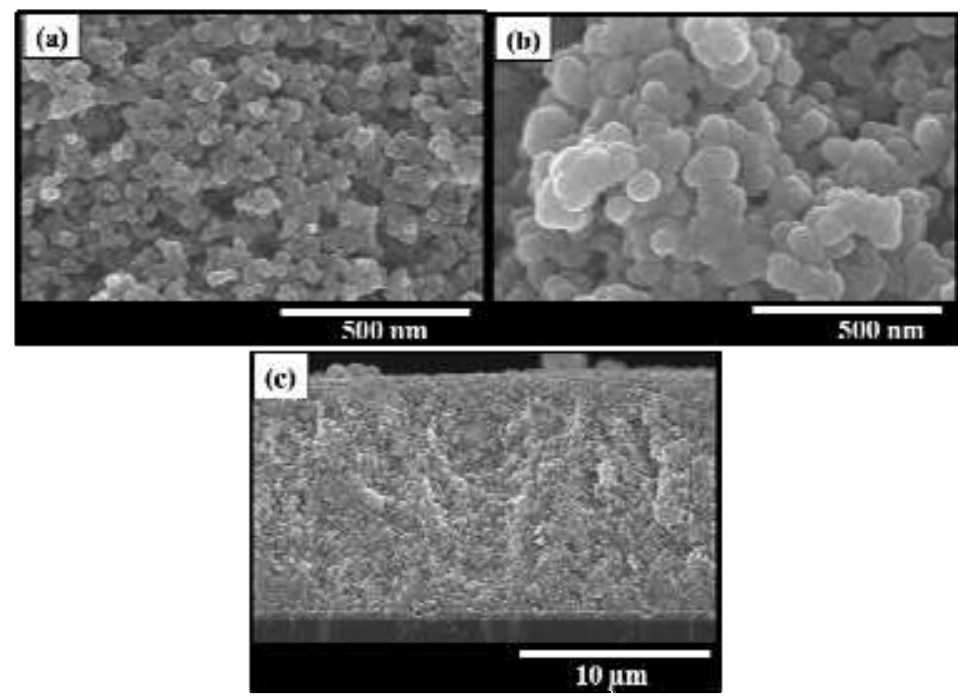

Fig. 6. Surface FESEM images of (a) $\mathrm{TiO}_{2}$ nanoparticles (b) electrophoretically deposited PANI/ $\mathrm{TiO}_{2}$ nanoparticulate thin film and (c) cross-section image of electrophoretically deposited PANI/ $\mathrm{TiO}_{2}$ nanoparticulate thin film. Reprinted with permission from [Ameen S., 2011], J. Nanosci. Nanotech. 11 (2011) 1559. (C) 2011, American Scientific Publishers.

The shifting of FTIR peaks, as shown in Fig. 7 (a) indicates the existence of the hydrogen bonding between the surface hydroxyl groups of $\mathrm{TiO}_{2}$ nanoparticles and the imine groups of PANI molecules (Somani, et al., 1999 \& Nivetal, et al., 2003). The UV-Vis spectra of pristine PANI and PANI/ $\mathrm{TiO}_{2}$ nanoparticulate thin film is shown in (Fig. 7 (b)). The pristine PANI exhibits two characteristics bands at 331 and $625 \mathrm{~nm}$ which correspond to $\pi-\pi^{*}$ transitions of the phenyl rings of PANI and $n-\Omega^{*}$ transitions respectively. In $\mathrm{PANI} / \mathrm{TiO}_{2}$ nanoparticulate thin film substrates, the peak at $269 \mathrm{~nm}$ retains its position, while the bands at $625 \mathrm{~nm}$ and 
$331 \mathrm{~nm}$ exhibit the blue shift to $599 \mathrm{~nm}$ and $321 \mathrm{~nm}$ respectively. These noticeable shifting and the intensity changes of the bands are ascribed to the bonding and the interaction between $\mathrm{TiO}_{2}$ and the quinoid ring of PANI due to the hydrogen bonding in the form of $\mathrm{NH} \cdot \mathrm{O}-\mathrm{Ti}$ in $\mathrm{PANI} / \mathrm{TiO}_{2}$ nanoparticulate thin film. The extensive XPS studies, as shown in Fig. 8 have been examined to investigate the bonding between PANI and $\mathrm{TiO}_{2}$ nanoparticles in PANI/ $\mathrm{TiO}_{2}$ nanoparticulate thin film. The four major peaks at $\sim 285.6 \mathrm{eV}$, $400.5 \mathrm{eV}, 530.9 \mathrm{eV}$ and $459.6 / 465.4 \mathrm{eV}$, are ascribed to carbon (C 1s), nitrogen (N 1s), oxygen (O 1s) and titanium (Ti 2p) respectively. The XPS studies favor the interaction of EPD PANI with $\mathrm{TiO}_{2}$ nanoparticles by the existence of hydrogen bonding between the imine group of PANI and the surface hydroxyl of $\mathrm{TiO}_{2}$ nanoparticles and thus, the electrophoretic deposition of PANI is a promising technique to construct the highly efficient PANI/ $\mathrm{TiO}_{2}$ nanoparticulate thin film.
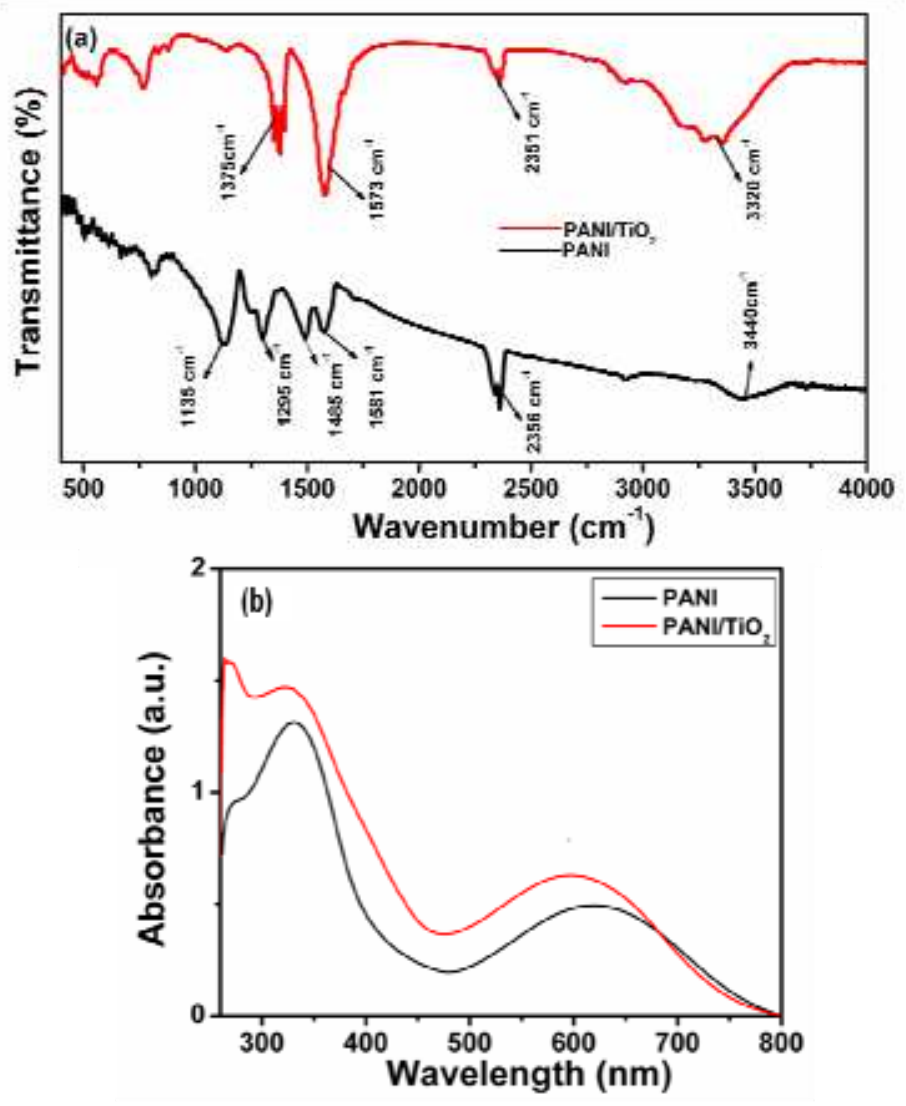

Fig. 7. (a) FT-IR spectra and (b) UV-Vis spectra of pristine PANI and electrophoretically deposited PANI/ $\mathrm{TiO}_{2}$ nanoparticulate thin film. Reprinted with permission from [Ameen S., 2011], J. Nanosci. Nanotech. 11 (2011) 1559. (C) 2011, American Scientific Publishers. 

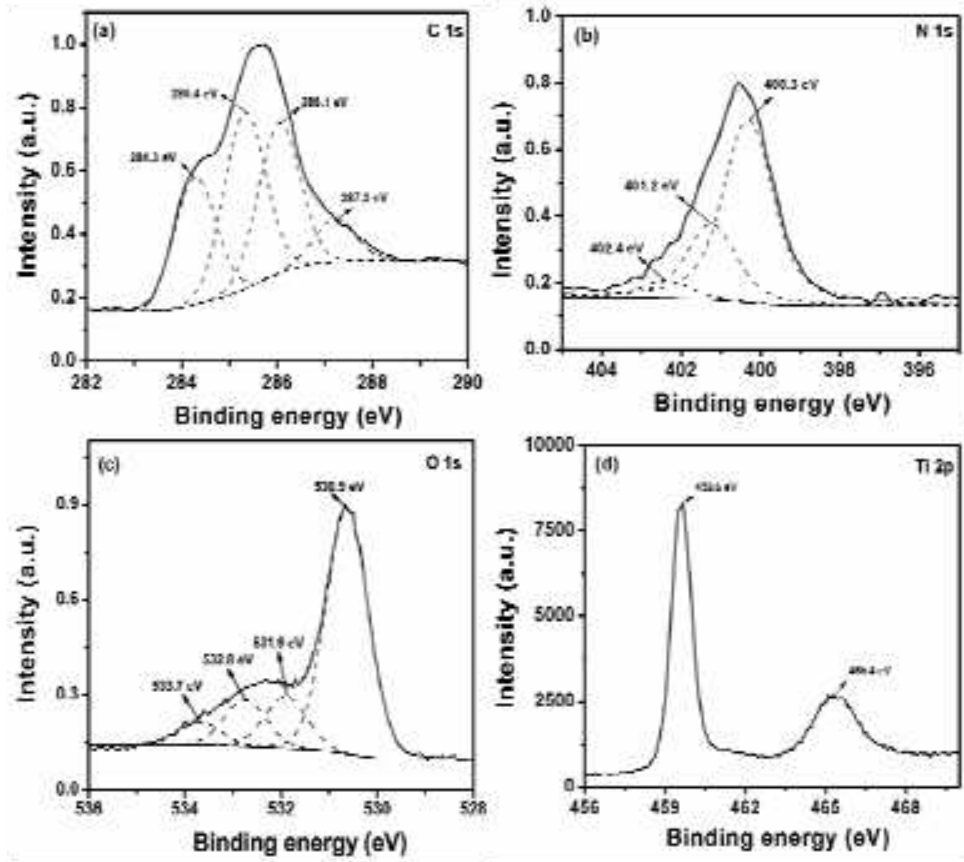

Fig. 8. (a) Resolved C1s, (b) N1s, (c) O1s and (d) Ti 2p XPS spectra of electrophoretically deposited $\mathrm{PANI} / \mathrm{TiO}_{2}$ nanoparticulate thin film. Reprinted with permission from [Ameen $\mathrm{S}$., 2011], J. Nanosci. Nanotech. 11 (2011) 1559. (C) 2011, American Scientific Publishers.

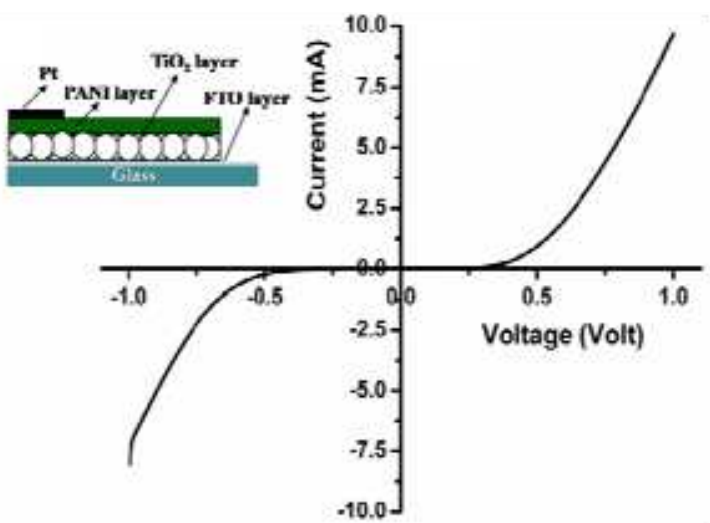

Fig. 9. $\mathrm{Pt} / \mathrm{PANI} / \mathrm{TiO}_{2}$ nanoparticulate diode. Insets show the schematic representation of the PANI/ $\mathrm{TiO}_{2}$ nanoparticulate heterostructure diode. Reprinted with permission from [Ameen S., 2011], J. Nanosci. Nanotech. 11 (2011) 1559. (C) 2011, American Scientific Publishers.

The current-voltage (I-V) characteristics of EPD PANI/ $\mathrm{TiO}_{2}$ nanoparticulate heterostructure was carried out at different temperatures $\left(25-150^{\circ} \mathrm{C}\right)$ with an applied voltage 
ranges from $-1 \mathrm{~V}$ to $+1 \mathrm{~V}$, as shown in Fig. 9. A schematic diagram of $\mathrm{Pt} / \mathrm{PANI} / \mathrm{TiO}_{2}$ nanoparticulate heterostructure diode is shown in the inset of Fig. 9. The I-V characteristic of $\mathrm{Pt} / \mathrm{PANI} / \mathrm{TiO}_{2}$ nanoparticulate heterostructure diode exhibits a rectifying and nonlinear behavior which might originate by the formation of schottky contact/barrier between $\mathrm{Pt}$ layer and EPD PANI/ $\mathrm{TiO}_{2}$ layer in $\mathrm{Pt} / \mathrm{PANI} / \mathrm{TiO}_{2}$ nanoparticulate heterostructure diode. Moreover, the ratio of forward $\left(I_{\mathrm{f}}\right)$ and reverse current $\left(I_{\mathrm{r}}\right)$, called as rectification ratio $\left(I_{\mathrm{f}} / I_{\mathrm{r}}\right)$ of the device is estimated as 7.0 at the bias voltage of $0.5 \mathrm{~V}$. The $I_{\mathrm{f}} / I_{\mathrm{r}}$ value indicates that the EPD PANI/ $\mathrm{TiO}_{2}$ nanoparticulate heterostructure shows a weak rectifying nature. The EPD $\mathrm{PANI} / \mathrm{TiO}_{2}$ heterostructure diode attains turn-on voltage of $\sim 0.40 \mathrm{~V}$ and derives quite high current of $\sim 0.25 \mathrm{~mA}$ at $298 \mathrm{~K}$. A broader breakdown voltage $(\sim 0.51 \mathrm{~V})$ and good leakage current of $\sim 0.9 \mathrm{~mA}$ are achieved by $\mathrm{Pt} / \mathrm{PANI} / \mathrm{TiO}_{2}$ nanoparticulate heterostructure diode. The low turn on voltage and high leakage current might result from the generation of high density of minority charge carriers from EPD PANI to $n$-type $\mathrm{TiO}_{2}$. In a reverse bias, $\mathrm{Pt} / \mathrm{PANI} / \mathrm{TiO}_{2}$ nanoparticulate heterostructure diode shows slightly high break down voltage $(\sim 0.55 \mathrm{~V})$ which could be explained by the hopping effect originated from the conjugated bonding of PANI and the geometry/ morphology of $\mathrm{TiO}_{2}$ nanoparticles. Therefore, the uniform and controlled thickness of PANI layer onto TiO2 nanoparticulates thin film substrate by the electrophoretic deposition provides the improved performance of the $\mathrm{p}-\mathrm{n}$ heterostructure devices.

\subsection{Plasma enhanced polymerization of PANI for heterostructure devices 5.2.1 Fabrication of $\mathrm{PANI} / \mathrm{TiO}_{2}$ heterostructure device}

The formation of an inorganic/organic heterojunction structure by depositing the plasma polymerized PANI on n-type nanocrystalline titania $\left(\mathrm{TiO}_{2}\right)$ thin film substrate has been reported by Ameen et al (Ameen, et al., 2009). Fig. 10 (a) demonstrates a porous $\mathrm{TiO}_{2}$ formed on the FTO substrates. The film is composed of the well crystalline $\mathrm{TiO}_{2}$ nanoparticles of size $\sim 25 \mathrm{~nm}$, as shown in Fig. 10 (c). It is seen in Fig. 10 (b) that the PANI molecules are well penetrated into the porous $\mathrm{TiO}_{2}$ thin film upon the plasma enhanced polymerization. The accumulation of $\mathrm{TiO}_{2}$ nanoparticles occurs after the deposition of PANI on the surface of $\mathrm{TiO}_{2}$ thin film, and could be seen in Fig. 10 (d). This assemblage confirms the internalization of plasma deposited PANI into porous $\mathrm{TiO}_{2}$ nanoparticles thin film substrates. The I-V characteristics for $\mathrm{PANI} / \mathrm{TiO}_{2}$ heterojunction structure, as shown in our reported work (Ameen, et al., 2009,), indicates that no barrier is apparently present because the I-V characteristic curve is almost linear. The forward bias current increases with an increased applied voltage and have attained almost the linear curve. The proficient current in PANI/TiO 2 is attributed to well penetration of PANI molecules into the pores of $\mathrm{TiO}_{2}$ nanoparticles layers which improves the degree of contact with $\mathrm{TiO}_{2}$ and thus decreases the series resistance of the cell while increasing the current. The efficient charge movement at the junction of PANI and $\mathrm{TiO}_{2}$ interfaces has made the heterojunction structure which behaves as a typical ohmic system. Moreover, in the reverse bias, the lower current is related to the decrease of the depletion layer because of the presence of the charge carriers at $\mathrm{TiO}_{2}$ nanoparticles thin film.

\subsubsection{Plasma deposited PANI on single and bilayer of $\mathrm{TiO}_{2}$ thin film for the fabrication of $\mathrm{PANI} / \mathrm{TiO}_{2}$ heterostructure diodes}

The organic/inorganic thin film is obtained by plasma enhanced p-type PANI deposited on the individual single and bilayer n-type $\mathrm{TiO}_{2}$ thin film electrodes for the fabrication of $\mathrm{p}-\mathrm{n}$ 


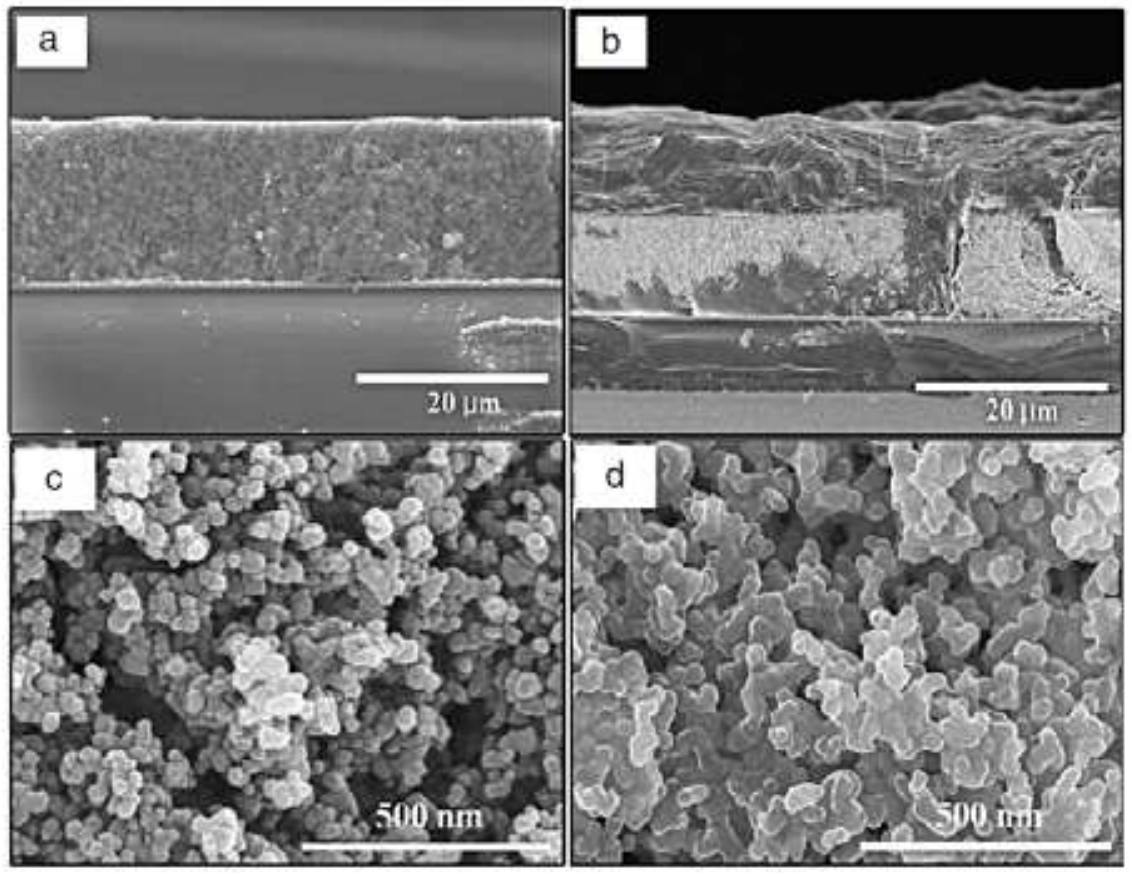

Fig. 10. Cross-sectioned FE-SEM images of (a) pristine $\mathrm{TiO}_{2}$ (b) Plasma enhanced deposited PANI/ $\mathrm{TiO}_{2}$ thin film and surface FESEM images of (c) pristine $\mathrm{TiO}_{2}$ (d) Plasma enhanced deposited PANI/ $\mathrm{TiO}_{2}$ thin film. Reprinted with permission from [Ameen S., 2009], Superlatt. Microstruc. 46 (2009) 745. () 2009, Elsevier Ltd.

heterostructure by Ameen et al (Ameen, et al., 2011). The single layer $\mathrm{TiO}_{2}$ electrode exhibits non uniform and less penetration of PANI molecules by plasma enhanced polymerization into the pores of $\mathrm{TiO}_{2}$ thin film. However, the extent of PANI deposition has drastically enhanced by the additional layer of $\mathrm{TiO}_{2}$ on the single layered electrode due to the uniform and well penetration of PANI into the pores of $\mathrm{TiO}_{2}$ nanoparticles.

The XPS characterizations suggest that the plasma polymerized PANI are interacted to $\mathrm{TiO}_{2}$ by the formation of hydrogen bonding between imine group of PANI and surface hydroxyl of $\mathrm{TiO}_{2}$. UV-Vis of $\mathrm{PANI} / \mathrm{TiO}_{2}$ thin film electrode exhibit the peaks at $324 \mathrm{~nm}$ corresponds to $\pi-\Omega^{*}$ transitions centered on the benzenoid and quinoid units. This peak appears with high intensity in PANI/bilayer $\mathrm{TiO}_{2}$ thin film electrode which indicates the enhanced deposition of PANI molecules on the surface of $\mathrm{TiO}_{2}$. It could be attributed that highly porous surface of bilayer $\mathrm{TiO}_{2}$ thin film absorbs large amount of PANI than the single layered $\mathrm{TiO}_{2}$ thin film, as described in previous report (Ameen, et al., 2011).

The fabricated $p-n$ heterostructure devices are comprised of plasma polymerized PANI ( $p-$ type) deposited on the single and bilayerTiO ${ }_{2}$ thin film (n-type) coated on FTO glass substrates with a top $\mathrm{Pt}$ thin layer contact. The I-V curve of the fabricated $\mathrm{PANI} /$ single layer $\mathrm{TiO}_{2}$ device attains low turn-on voltage of $\sim 0.4 \mathrm{~V}$ and delivers reasonably high current of $\sim 0.08 \mathrm{~mA}$ at 298 $\mathrm{K}$, as described in previous report (Ameen, et al., 2011). However, a breakdown voltage $(\sim 0.57$ V) with high leakage current of $\sim 0.6 \mathrm{~mA}$ is obtained by $\mathrm{Pt} / \mathrm{PANI} /$ single layer $\mathrm{TiO}_{2}$ 
heterostructure device. On comparison, $\mathrm{Pt} / \mathrm{PANI} /$ bilayer $\mathrm{TiO}_{2}$ heterostructure device shows the lower turn on voltage and low breakdown voltage with high leakage current than single layer $\mathrm{TiO}_{2}$ based heterostructure device. Here, the second layer of $\mathrm{TiO}_{2}$ in $\mathrm{PANI} /$ bilayer $\mathrm{TiO}_{2}$ provides a highly porous surface for the high loading of PANI molecules during the plasma enhanced polymerization and thus, produces high density of the minority charge carriers to ntype $\mathrm{TiO}_{2}$ thin film layer and results to the high leakage current with small turn-on voltage and breakdown voltage. It is attributed that the additional $\mathrm{TiO}_{2}$ thin film layer might increase the n-type character of the device. On the other hand, both the devices exhibit slight high reverse break down voltage $\left(\sim 0.58 \mathrm{~V}\right.$ in single layer $\mathrm{TiO}_{2}$ and $\sim 0.5 \mathrm{~V}$ in bilayer $\left.\mathrm{TiO}_{2}\right)$ which could be understood by considering the molecular geometry of PANI chains and geometry/morphology of $\mathrm{TiO}_{2}$ nanoparticles deposited on the FTO substrates which likely generate the hopping effect. The current densities reported by Sadia et al in the forward bias are considerably better than the data reported elsewhere on PANI based or other conducting polymer based heterostructure device (Dhawale, et al., 2008, Nadarajah, et al., 2008 \& Maeng, et al., 2008). Under light illumination, both the devices constitute the no current flowing condition i.e. called open circuit voltage condition $\left(\mathrm{V}_{\mathrm{OC}}\right)$ and the maximum current condition called short circuit current (JSC) at zero voltage condition. This phenomena is absent in I-V characteristics under dark condition, which means that the fabricated devices could absorb photons for the generation of current and having the photovoltaic behavior under light illumination and thus, $\mathrm{Pt} / \mathrm{PANI} /$ bilayer $\mathrm{TiO}_{2}$ heterostructure device is reported to achieve high $\mathrm{J}_{\mathrm{SC}}(\sim 0.32 \mathrm{~mA})$ with low $\mathrm{V}_{\mathrm{OC}}(\sim 0.343 \mathrm{~V})$ as compared with $\mathrm{Pt} / \mathrm{PANI} /$ single layer $\mathrm{TiO}_{2}$ heterostructure device $\left(\mathrm{J}_{\mathrm{SC}}=\sim 0.20 \mathrm{~mA}\right.$ and $\left.\mathrm{V}_{\mathrm{OC}}=\sim 0.462 \mathrm{~V}\right)$.

\section{Applications of PANI in dye sensitized solar cells (DSSCs)}

Organic solar cells have attracted considerable attention in recent years due to several advantages such as low cost, processing at low temperature, flexible and large area production etc (Thompson, et al., 2008, Gunes, et al., 2007 \& Bundgoard, et al., 2007). Usually, the organic materials are not good in carrier transport and thus, the power conversion efficiency is limited by the low dissociation probability of excitons and the inefficient hopping carrier transport (Shaw, et al. 2008 \& Sirringhaus, et al., 1999). Among various organic solar cells, polymer solar cells have demonstrated an impressive scale up on power conversion efficiency and improvement in lifetime. Right now a remarkable $8 \%$ power conversion efficiency has been reached at laboratory scale, 6-8\% for normal and 3-4\% for inverted configurations (Waldauf, et al., 2006, Steim, et al., 2010, 2008 \& Ameri, et al., 2009). Still, much work must be done in order to overcome the main difficulties observed for the technology i.e. enhancement of efficiency and lifetime. Thus, the need for novel materials acting as acceptors and donors, and the understanding of the interplay between interfaces (electrodes, optical spaces) are currently under an intense investigation. Semiconductor oxides have been applied extensively like antireflection coatings and scattering layers (Lee, et al., 2008), as interfacial layers in organic solar cells (Steim, et al., 2010, 2008) and as part of the active constituents of the device acting as electron transport materials in and hybrid DSSCs (Cantu, et al., 2010, 2006, 2007, 2006,Valls, et al., 2010, 2009). The semiconductor nanostructures are therefore proposed to combine with the organic materials to provide not only a large interface area between organic and inorganic components for exciton dissociation but also a fast electron transport in semiconductors. Hybrid solar cells are a mixture of nanostructures of both organic and inorganic materials. 
Therefore, they combine the unique properties of inorganic semiconductor nanoparticles with properties of organic/polymeric materials (Arici, et al., 2003). In addition to this, low cost synthesis, processability and versatile manufacturing of thin film devices make them attractive (Sariciftci, et al., 1992 \& Yu, et al., 1995). Also, inorganic semiconductor nanoparticles might have high absorption coefficients and particle size induced tunability of the optical band-gap. Thus, the hybrid solar cell is becoming interesting and attractive in recent years.

\section{1 $\mathrm{PANI} / \mathrm{TiO}_{2}$ thin film electrodes for the performance of DSSCs}

The $\mathrm{TiO}_{2} / \mathrm{PANI}$ and dye absorbed $\mathrm{TiO}_{2} / \mathrm{PANI}$ electrodes are prepared by plasma enhanced polymerization using aniline monomer for the fabrication of DSSCs by Ameen et al (Ameen, et al., 2009). The $\mathrm{TiO}_{2}$ thin film, prior to PANI deposition exhibits the particles of size $\sim 20-25 \mathrm{~nm}$, as shown in (Fig. 11 (b)). However, the proper attachment of plasma polymerized PANI on $\mathrm{TiO}_{2}$ thin film substrates (Fig. 11 (d)) and increases the size of $\mathrm{TiO}_{2}$ nanoparticles to $\sim 50-60 \mathrm{~nm}$ indicate the effects of the penetration of $\mathrm{PANI}$ into $\mathrm{TiO}_{2}$ nanoparticles. The current densityvoltage (J-V) performance of solar cell $\mathrm{FTO} / \mathrm{TiO}_{2} / \mathrm{Dye} / \mathrm{PANI} / \mathrm{Pt}$ and $\mathrm{FTO} / \mathrm{TiO}_{2} / \mathrm{PANI} / \mathrm{Pt}$ are shown in Fig.12 respectively. The electric contact of the hole conductor and the pore filling extent of the hole conductor into the dye-sensitized $\mathrm{TiO}_{2}$ film are the two important factors which determine the photovoltaic behaviors of the devices. It has been found that the solar cell based on $\mathrm{TiO}_{2}$ /Dye/PANI electrode executes great improvement in the overall conversion efficiency with the incorporation of dye layer on $\mathrm{TiO}_{2} / \mathrm{PANI}$ electrode and dramatically enhanced the photovoltaic properties such as open-circuit voltage $\left(\mathrm{V}_{\mathrm{OC}}\right)$, short-circuit current (Jsc) and fill factor (FF) as compared to $\mathrm{TiO}_{2} / \mathrm{PANI}$ electrode based DSSC. These improvements are resulted from the formation of $\mathrm{TiO}_{2} / \mathrm{PANI}$ thin film, where the photon generated electrons could freely travel at the interface of the PANI and $\mathrm{TiO}_{2}$ without decay, and dissociate into free charge carriers effectively.
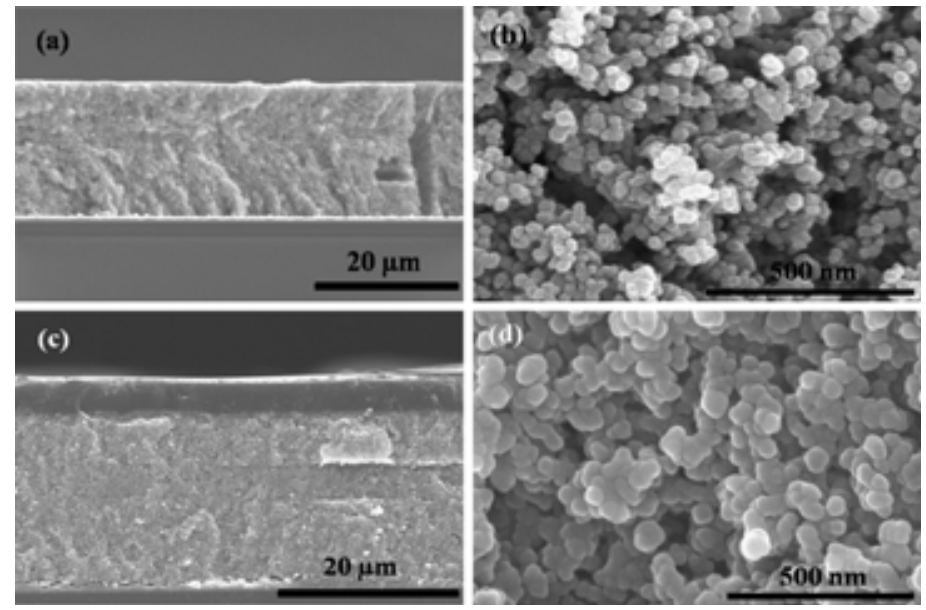

Fig. 11. (a) Cross-section and (b) surface view FESEM images of $\mathrm{TiO}_{2}$ deposited on FTO substrate. (c) and (d) show the cross-section and surface view FESEM images of Plasma enhanced deposited $\mathrm{PANI} / \mathrm{TiO}_{2}$ film. Reprinted with permission from [Ameen S. et al, 2009], J. Alloys Compd.164 (2009) 382. (C) 2009, Elsevier Ltd. 


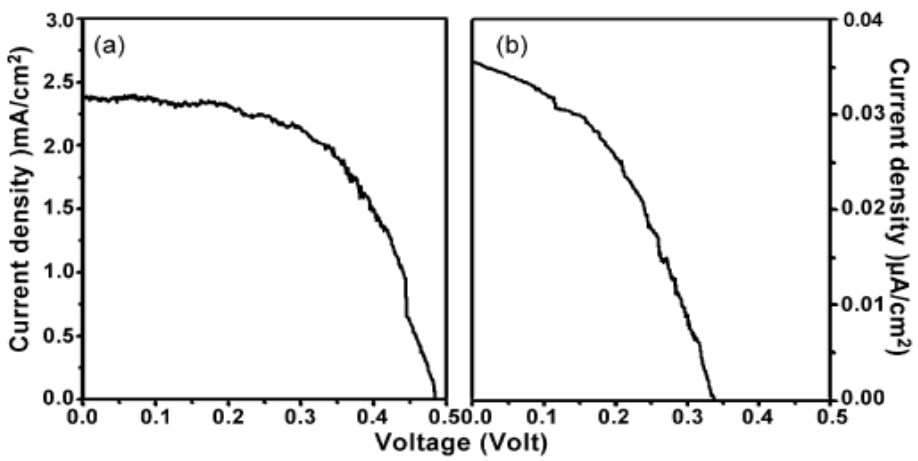

Fig. 12. J-V curve of fabricated solar cell (a) FTO/ $\mathrm{TiO}_{2} / \mathrm{Dye} / \mathrm{PANI} / \mathrm{Pt}$ (b) $\mathrm{FTO} / \mathrm{TiO}_{2} / /$ PANI/Pt. Reprinted with permission from [Ameen S. et al, 2009], J. Alloys Compd.164 (2009) 382. (c) 2009, Elsevier Ltd.

The DC conductivity vs $1000 / \mathrm{T}$ plots for the fabricated solar cells of $\mathrm{FTO} / \mathrm{TiO}_{2} /$ Dye/PANI/Pt and $\mathrm{FTO} / \mathrm{TiO}_{2} / / \mathrm{PANI} / \mathrm{Pt}$ are shown in Fig.13. It is cleared that the conductivity of $\mathrm{TiO}_{2} / \mathrm{PANI}$ is higher as compared to the pristine PANI. The room temperature conductivity of pristine PANI $\left(28.36 \times 10^{-3} \mathrm{ohm}^{-1} \mathrm{~cm}^{-1}\right)$ is lower than the room temperature conductivity of $\mathrm{PANI} / \mathrm{TIO}_{2}$ thin film $\left(75 \times 10^{-3} \mathrm{ohm}^{-1} \mathrm{~cm}^{-1}\right)$. The increase in conductivity might due to the increase of charged carrier concentration with improved mobility of the charged carriers. The rougher the surface, large-area defects and pinholes on PANI films exist and therefore, result to the high conduction of film. The effective electrical conductivity is thus, due to the retardation of both the transport of photoelectrons from counter electrode to hole conductor and the regeneration of the dye by the reduced-state hole conductors. Such improvements could suppress the recombination of photoelectrons, injected into the conduction band of $\mathrm{TiO}_{2}$ from PANI and retards the internal resistance of the device.

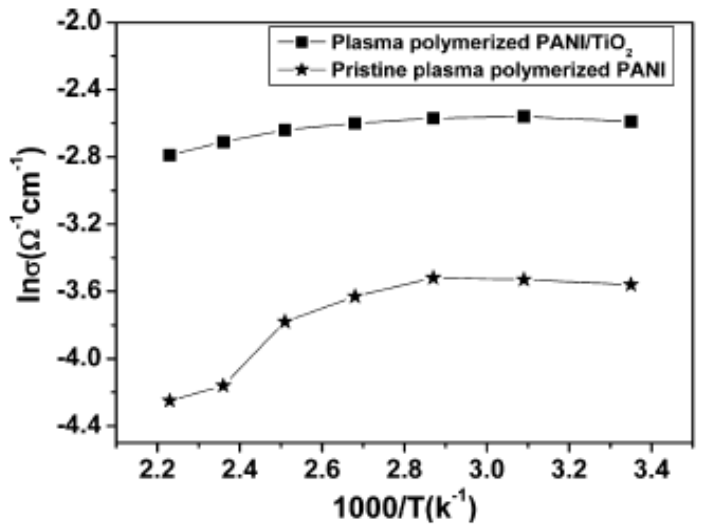

Fig. 13. Plots of DC conductivity vs $1000 / \mathrm{T}$ for pristine PANI and plasma enhanced deposited PANI/ $\mathrm{TiO}_{2}$ thin film. Reprinted with permission from [Ameen S. et al, 2009], J. Alloys Compd.164 (2009) 382. (C 2009, Elsevier Ltd 
AC impedance of FTO/TiO $/ /$ PANI/Pt (Fig.14(a)) and $\mathrm{TiO}_{2} /$ Dye/PANI (Fig.14(b)) thin film electrode based DSSCs under the illumination of $100 \mathrm{~mW} / \mathrm{cm}^{2}$ (AM1.5) by applying a $10 \mathrm{mV}$ AC signal at the frequency range from $10 \mathrm{~Hz}$ to $100 \mathrm{kHz}$ are also measured by Sadia et al. A very high $R_{\mathrm{P} / \mathrm{TCO}}$ of $52.4 \Omega$ and $\mathrm{R}_{\mathrm{CT}}$ of $3700 \Omega$ was observed for $\mathrm{TiO}_{2} / \mathrm{PANI}$ electrodes based cells. Comparatively, $\mathrm{TiO}_{2} / \mathrm{Dye} / \mathrm{PANI}$ based device showed the low $\mathrm{R}_{\mathrm{P} / \mathrm{TCO}}(35.8 \Omega)$ and $R_{\text {Ст }}(81.9 \Omega)$ due to the influence of dye layer which is placed between the $\mathrm{TiO}_{2}$ and PANI layer of the electrode. It is found that the value of $\mathrm{R}_{\mathrm{CT}}$ in $\mathrm{TiO}_{2} / \mathrm{Dye} / \mathrm{PANI}$ based device is very low as compared to the $\mathrm{R}_{\mathrm{CT}}$ of $\mathrm{TiO}_{2} / \mathrm{PANI}$ based device. Thus, it explains the high electron transfer at the junction of $\mathrm{TiO}_{2}$ and PANI in $\mathrm{TiO}_{2} /$ Dye/PANI based device, resulting in the high photocurrent density and overall conversion efficiency.
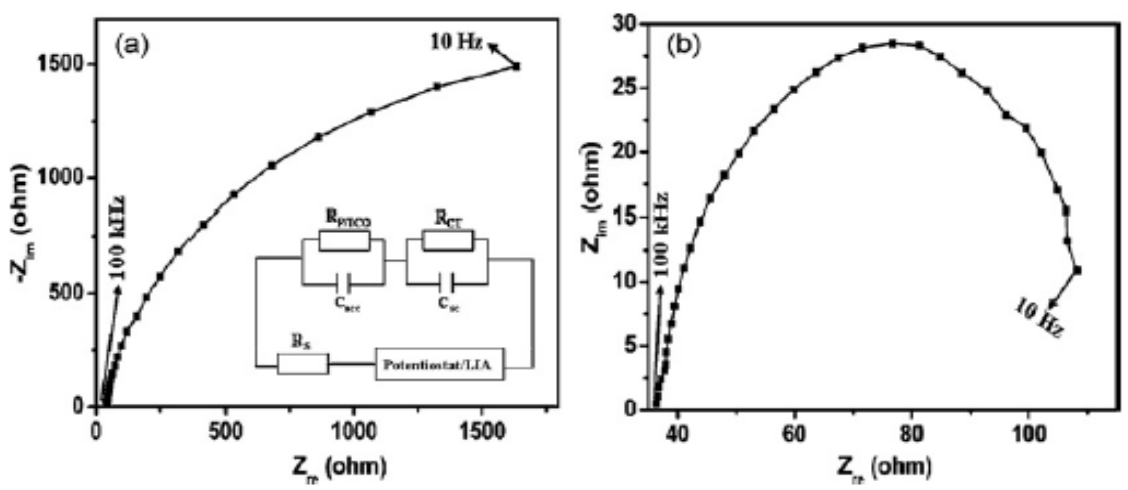

Fig. 14. AC impedance of (a) $\mathrm{FTO} / \mathrm{TiO}_{2} / / \mathrm{PANI} / \mathrm{Pt}$ and (b) $\mathrm{TiO}_{2} /$ Dye/PANI thin film electrode based DSSCs at the frequency range from $10 \mathrm{~Hz}$ to $100 \mathrm{kHz}$. Inset shows the equivalent circuit model of the device. Reprinted with permission from [Ameen S. et al, 2009], J. Alloys Compd.164 (2009) 382. (c) 2009, Elsevier Ltd.

\subsection{PANI thin film electrode as counter electrode for DSSCs}

Conducting polymers generally show p-type semiconducting behavior, good specific capacitance and catalytic activity for the reduction of $\mathrm{I}_{3}$ - ion. Owing to their specialty, the conducting polymers are used as counter electrode (CE) materials for DSSCs. In 2008, Saito et al reported the preparation of the counter electrode using p-toluenesulfonate (PEDOTTsO) or polystyrenesulfonate (PEDOT-PSS) doped poly (3, 4ethylenedioxythiophene) (PEDOT) for DSSCs (Saito et al., 2004). They achieved a comparably high conversion efficiency of $4.6 \%$ with $\mathrm{J}_{\mathrm{SC}}=11.2 \mathrm{~mA} / \mathrm{cm}^{2}, \mathrm{~V}_{\mathrm{OC}}=670 \mathrm{mV}$ and $\mathrm{FF}=0.61$ with the fabricated DSSCs. Consecutively, the composite films of graphene and PEDOT-PSS deposited on indium tin oxide (ITO) substrates by spin coating and applied as counter electrodes of DSSCs. The prepared CE exhibited high transmittance $(>80 \%)$ at visible wavelengths and high electrocatalytic activity as compared to the above system with the similar conversion efficiency $(4.5 \%)$. Q. Li et al group manufactured a microporous polyaniline (PANI) and applied as CE for the fabrication of DSSCs (Li, et al., 2008). The advanced microporous PANI CE with particle diameter of $100 \mathrm{~nm}$ possessed the lower charge-transfer resistance and higher electrocatalytic activity for the redox reaction. DSSC fabricated with microporous PANI CE exhibited reasonably high overall conversion 
efficiency of 7.15\% i.e. compared to DSSC with Pt CE. This report could open the utilization of the simple preparation technique with low cost and excellent photoelectric properties of PANI based counter electrode as appropriate alternative CE materials for DSSCs. Furthermore, J. Wu et al prepared polypyrrole (PPy) nanoparticle and deposited on a fluorine-doped tin oxide (FTO) glass for the construction of PPy counter electrode and applied to DSSC (Wu, et al., 2008). The fabricated DSSC achieved a very high conversion efficiency of $7.66 \%$ owing to its smaller charge transfer resistance and higher electrocatalytic activity for the $\mathrm{I}_{2} / \mathrm{I}^{-}$redox reaction. After this significant breakthrough, $\mathrm{K}$. M. Lee et al developed poly (3, 4-alkylenedioxythiophene) based CE by electrochemical polymerization on FTO glass substrate for DSSC (Lee, et al., 2009). A high conversion efficiency of $7.88 \%$ was acquired by the fabricated DSSC which attributed to the increased effective surface area and good catalytic properties for $\mathrm{I}_{3}{ }^{-}$reduction. Progressively, the nanostructured polyaniline films were grown on FTO glass using cyclic voltammetry (CV) method at room temperature and applied as counter electrode for DSSCs. They found that the controlled thickness of nanostructured polyaniline $(>70 \mathrm{~nm})$ by the used method increased the reactive interfaces, which conducted the charge transfer at the interface and low resistance hinders electronic transport within the film. The fabricated DSSCs achieved a high overall conversion efficiency of $4.95 \%$ with very high JSC of $12.5 \mathrm{~mA} / \mathrm{cm}^{2}$. Importantly, the nanostructured PANI electrode showed the $11.6 \%$ improvement in JSC as compared to DSSC with an electrodeposited platinum counter electrode (Zhang, et al., 2010). Recently, Ameen et al synthesized the undoped and sulfamic acid (SFA) doped PANI nanofibers (NFs) via template free interfacial polymerization process and deposited on FTO substrates using spin coating to prepare counter electrode for DSSCs (Ameen, et al., 2010).

\subsection{Sulfamic acid doped PANI Nanofibers counter electrode for DSSCs}

Ameen et al developed a simple interfacial polymerization method for the synthesis of PANI nanofibers (NFs) and its doping with sulfamic acid (SFA) to increase the conductivity (Ameen, et al., 2010). These undoped and SFA doped PANI NFs were applied as new counter electrodes materials for the fabrication of the highly efficient DSSCs. The selection of SFA was based on its exclusively important properties such as high solubility, easy handling, nonvolatile stable solid acid, and low corrosiveness. The proposed doping mechanism for PANI with SFA is shown in Fig. 15. PANI NFs exhibit well-defined fibrous morphology with the diameter of $30 \mathrm{~nm}$ (Fig. 16 (b)) and the diameter of PANI NFs has considerably increased to $\sim 40 \mathrm{~nm}$ after doping with SFA, as shown in Fig. 16 (a). The chemical doping of SFA causes some aggregation of PANI NFs, and therefore, the formation of voids into the fibrous network of PANI NFs are noticed. The TEM images of PANI NFs (Fig. 16 (c)) and SFA-doped PANI NFs (Fig. 16 (d)) justifies the doping effect on the morphology of PANI NFs. The entrapped SFA into the fibers of PANI results to the increase of average diameter by $\sim 40 \mathrm{~nm}$ as compared to undoped PANI NFs.

The UV-Vis of SFA doped PANI-NFs, as shown in Fig. 17 (a), exhibits a slight blue shift of the peak at $296 \mathrm{~nm}$ from $298 \mathrm{~nm}$ and a considerably large red shift at $380 \mathrm{~nm}$ from $358 \mathrm{~nm}$ which indicates the interactions between SFA dopants and the quinoid ring of emeraldine salt (ES) and facilitate the charge transfer between the quinoid unit of ES and the dopant via highly reactive imine groups. The CV curves (Fig. 17 (b)) of SFA-doped PANI NFs electrode attains a reasonably high anodic peak current $\left(I_{\mathrm{a}}\right)$ of $0.24 \mathrm{~mA} / \mathrm{cm}^{2}$ and cathodic peak current $\left(I_{\mathrm{c}}\right)$ of $-0.17 \mathrm{~mA} / \mathrm{cm}^{2}$ with a considerably high value of switching point $\left(0.22 \mathrm{~mA} / \mathrm{cm}^{2}\right)$. 
However, the undoped PANI NFs electrode exhibits a low $I_{\mathrm{a}}$ of $0.21 \mathrm{~mA} / \mathrm{cm}^{2}$ and $I_{\mathrm{c}}$ of -0.2 $\mathrm{mA} / \mathrm{cm}^{2}$ with a low switching point $\left(0.17 \mathrm{~mA} / \mathrm{cm}^{2}\right)$. These results suggest that the high peak current might increase the redox reaction rate at SFA-doped PANI NFs counter electrode, which may attribute to its high electrical conductivity and surface area.

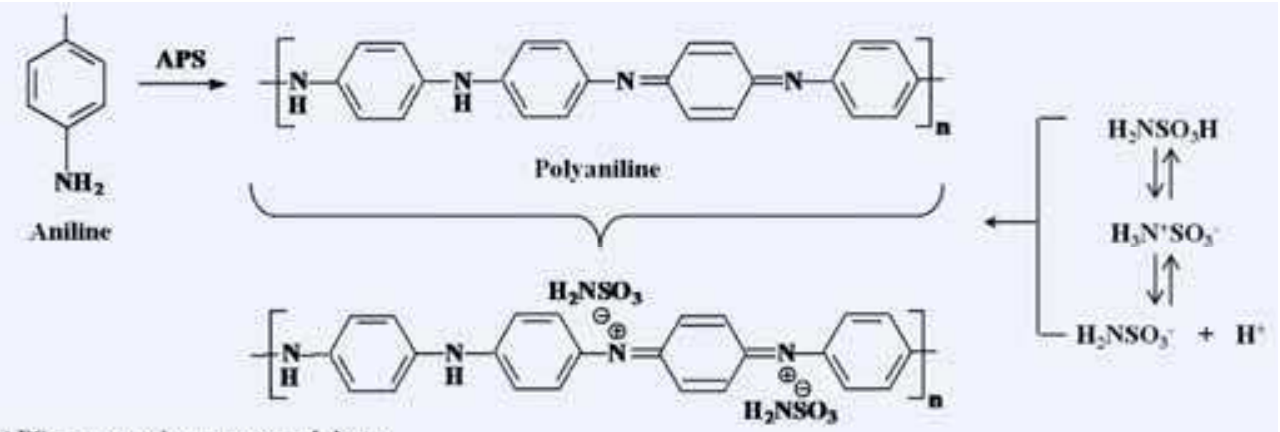

APS = ammonium peroxysulphate

Suffamic doped polyaniline

Fig. 15. Proposed mechanism of sulfamic doping into PANI NFs.

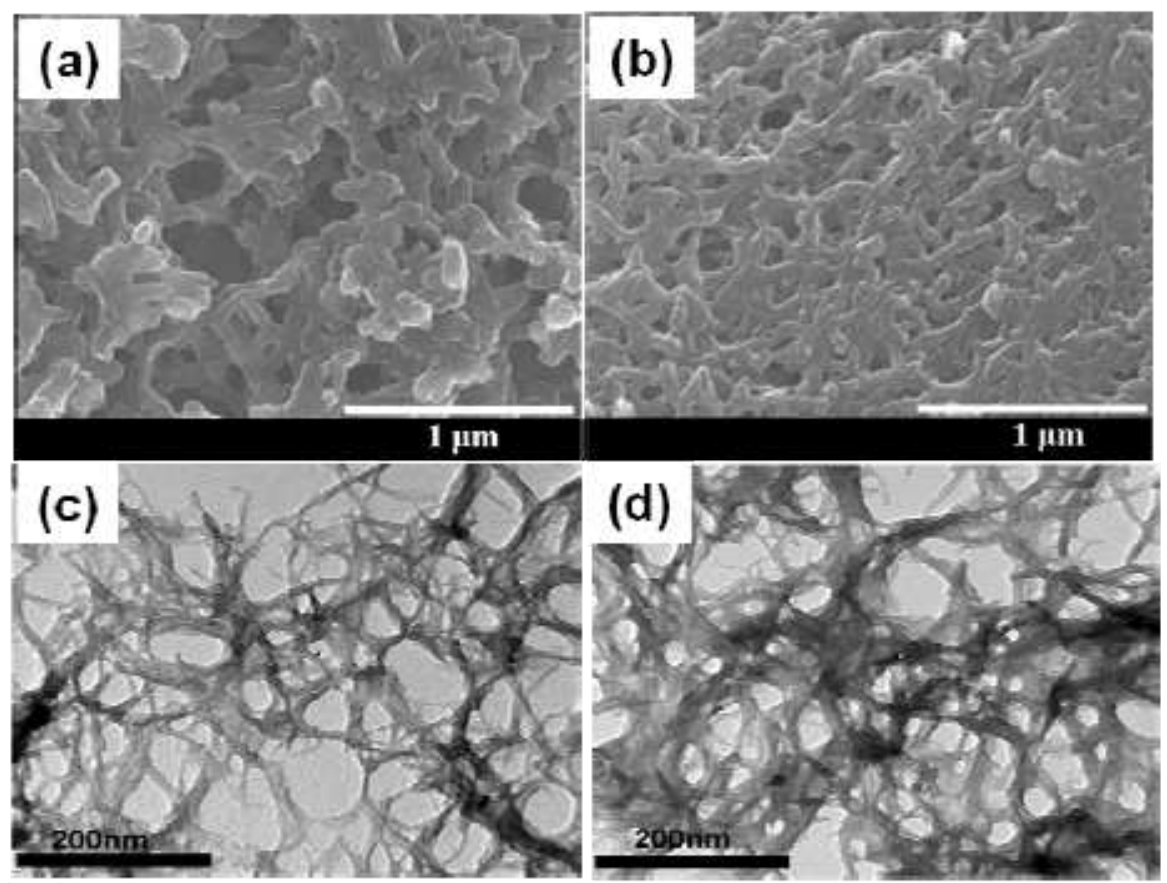

Fig. 16. FESEM images of (a) SFA doped PANI NFs and (b) PANI NFs. TEM images of (c) PANI and (d) SFA doped PANI NFs. Reprinted with permission from [Ameen S. et al, 2010], J. Phys. Chem. C 114 (2010) 4760. (C) 2010, ACS Publications Ltd. 

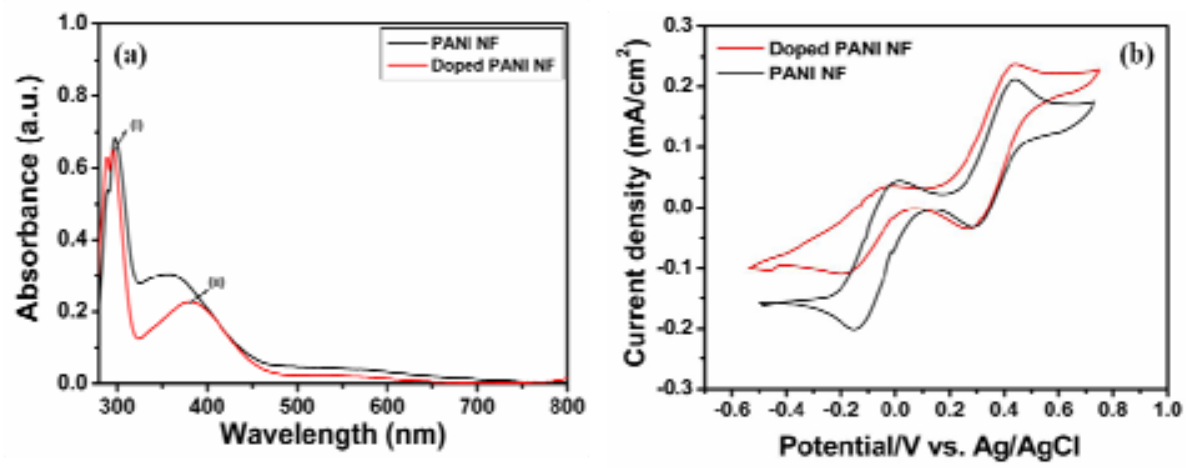

Fig. 17. (a) UV-vis spectra of PANI NFs and SFA-doped PANI NFs. (b) Cyclic voltammetry of iodide species on PANI NFs and SFA doped PANI NFs electrodes in acetonitrile solution with $10 \mathrm{mM} \mathrm{LiI}, 1 \mathrm{mM} \mathrm{I}_{2}$, and $0.1 \mathrm{M} \mathrm{LiClO}_{4}$. Reprinted with permission from [Ameen S. et al, 2010], J. Phys. Chem. C 114 (2010) 4760. (C) 2010, ACS Publications Ltd.

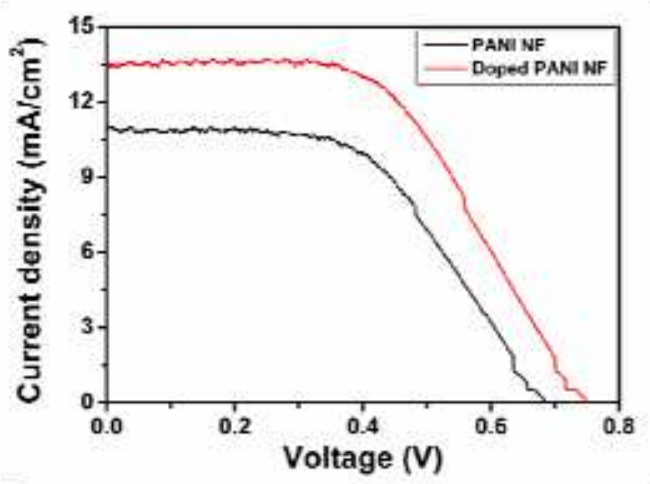

Fig. 18. J-V curve of fabricated solar cell of PANI NFs and SFA doped PANI NFs as counter electrodes under light illumination of $100 \mathrm{~mW} / \mathrm{cm}^{2}$. Reprinted with permission from [Ameen S. et al, 2010], J. Phys. Chem. C 114 (2010) 4760. () 2010, ACS Publications Ltd.

The Fig. 18 shows that the DSSCs fabricated with SFA-doped PANI NFs counter electrode achieve a high conversion efficiency ( $\eta$ ) of $5.5 \%$ with a high short circuit current (JsC) of 13.6 $\mathrm{mA} / \mathrm{cm}^{2}$, open circuit voltage $\left(\mathrm{V}_{\mathrm{OC}}\right)$ of $0.74 \mathrm{~V}$, and fill factor $(\mathrm{FF})$ of 0.53 . The conversion efficiency increases by $\sim 27 \%$ and thus, after SFA doping of PANI NFs the conversion efficiency reaches the value of $5.5 \%$ than that of DSSC fabricated with PANI NFs counter electrode $(4.0 \%)$. Further, the SFA-doped PANI NFs counter electrode has significantly increased the JSC and $\mathrm{V}_{\mathrm{OC}}$ of $\sim 20 \%$ and $\sim 10 \%$, respectively, as compared to the DSSC fabricated with PANI NFs counter electrode. It indicates that the SFA doping has increased the fast reaction of $\mathrm{I}^{-} / \mathrm{I}_{3}-$ species at counter electrode and therefore, the superior photovoltaic properties such as $\eta$, JSC, and $\mathrm{V}_{\mathrm{OC}}$ of the cell are attributed to the sufficiently high conductivity and electrocatalytic activity of doped PANI NFs, which alleviates the reduction of $\mathrm{I}_{3}$ - at the thin SFA-doped PANI NFs layers. Importantly, the IPCE curves of DSSCs fabricated with PANI NFs counter electrode exhibit the low IPCE of $\sim 54 \%$ in the absorption range of $400-650 \mathrm{~nm}$. 
The IPCE value has prominently increased by $~ 70 \%$ with the SFA doped PANI NFs counter electrode-based DSSCs. It is noteworthy that the IPCE of the device is considerably enhanced by $\sim 24 \%$ upon SFA doping on PANI NFs-based counter electrodes. The enhanced IPCE in DSSCs with SFA-doped PANI NFs electrode results in the high JSC and photovoltaic performance, which are related to its high electrical conductivity and the higher reduction of $\mathrm{I}_{3}$ to I- in the electrolyte at the interface of PANI NFs layer and electrolyte.

\section{Fabrication of DSSCs with metal oxide nanomaterials photoanodes}

In DSSCs, the choice of semiconductor is governed by the conduction band energy and density of states which facilitate the charge separation and minimizing the recombination. Secondly, the high surface area and morphology of semiconductor are important to maximize the light absorption by the dye molecules while maintaining the good electrical connectivity with the substrate (Baxtera, et al., 2006). The semiconducting metal oxides such as $\mathrm{TiO}_{2}, \mathrm{ZnO}$ and $\mathrm{SnO}_{2}$ etc have shown good optical and electronic properties and are accepted as the effective photoelectrode materials for DSSCs. These metal oxide nanostructures present discrete morphologies of nanoparticles (Ito, et al., 2008) nanowires (Law, et al., 2005 \& Feng, et al., 2008) and nanotubes (Macak, et al., 2005 \& Mor et al., 2005) which are the key component in DSSCs for the effective dye adsorption and the efficient electron transfer during the working operation of DSSCs. To improve the light harvesting efficiency, the metal oxide nanostructures must possess high surface to volume ratio for high absorption of dye molecules. These metal oxide nanostructures are usually prepared by the methods like hydrothermal synthesis (Zhang, et al., 2003 \& Wang et al., 2009) template method (Ren, et al., 2009 \& Tan, et al., 2008) electrodeposition (Tsai, et al., 2009) and potentiostatic anodization (Chen, et al., 2009 \& kang, et al., 2009) and are important for improving the photovoltaic properties of DSSCs such as $\mathrm{JSC}_{\mathrm{SC}} \mathrm{V}_{\mathrm{OC}}$, FF and conversion efficiency. Out of these, $\mathrm{TiO}_{2}$ has been intensively investigated for their applications in photocatalysis and photovoltaic (Regan, et al., 1991 \& Duffie, et al., 1991). Particularly in DSSCs, the porous nature of nanocrystalline $\mathrm{TiO}_{2}$ films provides the large surface for dyemolecule adsorption and therefore, the suitable energy levels at the semiconductor-dye interface (the position of the conduction-band of $\mathrm{TiO}_{2}$ being lower than the excited-state energy level of the dye) allow for the effective injection of electrons from the dye molecules to the semiconductor. Compared with other photovoltaic materials, anatase phase $\mathrm{TiO}_{2}$ is outstanding for its stability and wide band gap and thus, widely used in the devices (Gratzel, et al., 2001). On the other hand, $\mathrm{ZnO}$ nanomaterials are chosen as an alternative material to $\mathrm{TiO}_{2}$ photoanode due to its wide-band-gap with higher electronic mobility which would be favorable for the efficient electron transport, with reduced recombination loss in DSSCs. Studies have already been reported on the use of $\mathrm{ZnO}$ material photoanode for the application in DSSCs. Although the conversion efficiencies of $\mathrm{ZnO}(0.4-5.8 \%)$ is comparably lower than $\mathrm{TiO}_{2}(11 \%)$ but still $\mathrm{ZnO}$ is a distinguished alternative to $\mathrm{TiO}_{2}$ due to its ease of crystallization and anisotropic growth. In this part of the chapter, the various nanostructures of $\mathrm{TiO}_{2}$ and $\mathrm{ZnO}$ have been briefly summarized for the application for DSSCs.

\subsection{Various $\mathrm{TiO}_{2}$ nanostructures photoanodes for DSSCs 7.1.1 Photoanodes with $\mathrm{TiO}_{2}$ nanotubes}

$\mathrm{TiO}_{2}$ nanotubes (NTs) arrays are generally synthesized by the methods like electrochemical approach (Zwilling, et al., 1999 \& Gong, et al., 2001) layer-by-layer assembly (Guo, et al., 
2005) template synthesis, sol-gel method (Martin, et al., 1994, Limmer, et al., 2002 \& Lakshmi, et al., 1997) etc and are the effective photoanode for the fabrication of DSSCs. The reported methods for the synthesis of $\mathrm{TiO}_{2}$ NTs provide low yield and demand advanced technologies with the high cost of templates (anodic aluminum oxide, track-etched polycarbonate or the amphiphilic surfactants). A. J. Frank obtained the bundle-free and crack-free NT films by using the supercritical $\mathrm{CO}_{2}$ drying technique and found that the charge transport was considerably increased with the decreased of NTs bundles which created the additional pathways through the intertube contacts. However, J. H. Park et al. reported a simple and inexpensive methodology for preparing $\mathrm{TiO}_{2}$ NTs arrays on FTO glass and applied as photoanodes for DSSCs which exhibited the significantly high overall conversion efficiency of $7.6 \%$ with high $\mathrm{JSC}_{\mathrm{SC}}$ of $16.8 \mathrm{~mA} / \mathrm{cm}^{2}, \mathrm{~V}_{\mathrm{OC}}$ of $0.733 \mathrm{~V}$ and a fill factor (FF) of 0.63 . The enhanced photovoltaic performance was attributed to the reduced charge recombination between photoinjected electrons in the substrate via tubular morphology of $\mathrm{TiO}_{2}$ photoanode (Park, et al., 2008).

\subsubsection{Photoanodes with $\mathrm{TiO}_{2}$ nanorods}

The Highly crystalline $\mathrm{TiO}_{2}$ nanorods (NRs) with lengths of $\sim 100-300 \mathrm{~nm}$ and diameters of $\sim 20-30 \mathrm{~nm}$ were grown by J. Jui et al using the hydrothermal process with cetyltrimethylammonium bromide surfactant solution (Jiu, et al., 2006). In this synthesis, the length of nanorods was substantially controlled and maintained by the addition of a triblock copolymer poly-(ethylene oxide) 100-poly (propylene oxide) 65-poly (ethylene oxide) 100 (F127) and polymer decomposed after sintering of $\mathrm{TiO}_{2}$ nanorods at high temperatures. The fabricated DSSCs attained a high overall conversion efficiency of $7.29 \%$ with considerably high $\mathrm{V}_{\mathrm{OC}}$ of $0.767 \mathrm{~V}$ and fill factor of 0.728 . The enhancement in the photovoltaic properties was attributed to increase the ohmic loss and high electron transfer through $\mathrm{TiO}_{2}$ NRs. As compared to P-25 based DSSCs, the less amount of dye was absorbed by the $\mathrm{TiO}_{2}$ NRs photoanode might due to the larger size of the nanorods and therefore, result a slightly lower photocurrent density of $13.1 \mathrm{~mA} / \mathrm{cm}^{2}$. B. Liu group proposed a hydrothermal process to develop the oriented single-crystalline $\mathrm{TiO}_{2} \mathrm{NRs}$ or nanowires on a transparent conductive substrate (Liu, et al., 2009). The DSSCs fabricated with $\mathrm{TiCl}_{4}$ generated $4 \mu \mathrm{m}$-long rutile $\mathrm{TiO}_{2} \mathrm{NRs}$ electrode and demonstrated relatively low light-toelectricity conversion efficiency of $3 \%$ with $\mathrm{J}_{\mathrm{SC}} \sim 6.05 \mathrm{~mA} / \mathrm{cm}^{2}, \mathrm{~V}_{\mathrm{OC}}$ of $\sim 0.71 \mathrm{~V}$, and FF of 0.7 . The device delivered the improved IPCE of $\sim 50 \%$ at the peak of the dye absorption. The improved $\mathrm{V}_{\mathrm{OC}}$ and $\mathrm{FF}$ revealed that the $\mathrm{TiCl}_{4}$ treatment decreased the surface recombination. Conclusively, $\mathrm{TiO}_{2}$ NRs improved the dye adsorption and the optical density through the surface of oriented NRs.

\subsubsection{Photoanodes with $\mathrm{TiO}_{2}$ nanowires}

Single-crystal-like anatase $\mathrm{TiO}_{2}$ nanowires (NWs) as compared to NRs and NTs morphology are extensively applied as photoanode for the fabrication of DSSCs. The perfectly aligned morphology of $\mathrm{TiO}_{2}$ NWs and networks of NWs could be achieved by the solution, electrophoretic and hydrothermal process due to the "oriented attachment" mechanism. The aligned $\mathrm{TiO}_{2}$ network with single-crystal anatase NWs conducted the high rate of electron transfer and achieved significantly high overall conversion efficiency of $9.3 \%$ with high JSC of $19.2 \mathrm{~mA} / \mathrm{cm}^{2}, \mathrm{~V}_{\mathrm{OC}}$ of $0.72 \mathrm{~V}$, and FF of 0.675 . The improved photovoltaic performance was ascribed to the network structure of single-crystal-like anatase NWs which acquired a high surface to volume ratio and thus, presented the high IPCE of $\sim 90 \%$. Recently, J. K. Oh 
et al reported the branched $\mathrm{TiO}_{2}$ nanostructure photoelectrodes for DSSCs with $\mathrm{TiO}_{2} \mathrm{NWs}$ as a seed material (Oh, et al., 2010). The prepared $\mathrm{TiO}_{2}$ electrode possessed a three-dimensional structure with rutile phase and showed high conversion efficiency of $4.3 \%$ with high JSC of $12.18 \mathrm{~mA} / \mathrm{cm}^{2}$. Compared to DSSCs with $\mathrm{TiO}_{2} \mathrm{NWs}$, the cell performance and JsC was enhanced by 2 times, which was due to the increased specific surface area and the roughness factor. However, the lower FF was originated from the branches of $\mathrm{TiO}_{2}$ electrodes, resulting in the reduction of grain boundaries.

\subsection{Various $\mathrm{ZnO}$ nanostructures photoanodes for DSSCs \\ 7.2.1 Photoanodes with ZnO nanoparticles}

The techniques like vapor liquid solid, chemical vapor deposition, electron beam evaporation, hydro thermal deposition, electro chemical deposition and thermal evaporation etc are generally applied for the synthesis of $\mathrm{ZnO}$ nanostructures. Out of these, the chemical solution method is the simplest procedure for achieving uniform $\mathrm{ZnO}$ nanoparticles (NPs) thin films and delivers almost the same performance as that of nanocrystalline $\mathrm{TiO}_{2}$ with similar charge transfer mechanism between the dye and semiconductor. The synthesis of ZnO NPs is reported by the preparation of $\mathrm{ZnO}$ sols with zinc acetate as precursor and lithium hydroxide to form homogeneous ethanolic solutions (Spanhel, et al., 1991 \& Keis, et al., 2001). Several researchers have fabricated DSSCs using sol-gel-derived ZnO NPs films and reported the low conversion efficiencies with values generally around 0.4-2.22\% (Redmond, et al., 1994, Rani, et al., 2008 \& Zeng, et al., 2006). Highly active $\mathrm{ZnO}$ nanoparticulate thin film through a compression method was prepared for high dye absorption by Keis et al for the fabrication of DSSCs (Keis, et al., 2002, 2002). The morphology of ZnO NPs, synthesized by a sol-gel route exhibited an average size of $150 \mathrm{~nm}$. The thin film photoelectrodes were prepared by compressing the ZnO NPs powder under a very high pressure and the DSSCs fabricated with the obtained film achieved a very high overall conversion efficiency of $5 \%$ under the light intensity of $10 \mathrm{mWcm}^{2}$.

\subsubsection{Photoanodes with $\mathrm{ZnO}$ nanosheets and other nanostructures}

$\mathrm{ZnO}$ nanosheets (NSs) are quasi-two-dimensional structures that could be fabricated by a rehydrothermal growth process of hydrothermally grown ZnO NPs (Suliman, et al., 2007). M. $\mathrm{S}$. Akhtar et al prepared sheet-spheres morphology of $\mathrm{ZnO}$ nanomaterials through citric acid assisted hydrothermal process with $5 \mathrm{M} \mathrm{NaOH}$ solution (Akhtar, et al., 2007). The high conversion efficiency and high photocurrent of ZnO NSs based DSSCs was attributed to the effective high light harvesting by the maximum dye absorption via $\mathrm{ZnO}$ NSs film surface which promoted a better pathway for the charge injection into the $\mathrm{ZnO}$ conduction layer. Sequentially, C. F. Lin et al fabricated a prepared $\mathrm{ZnO}$ nanobelt arrays on the FTO substrates by an electrodeposition method and applied as photoelectrode for the fabrication of DSSCs (Lin, et al., 2008). Y. F. Hsu et al had grown a 3-D structure ZnO tetrapod nanostrcutures, comprised of four arms which were extended from a common core (Hsu, et al., 2008 \& Chen, et al., 2009). The length of the arms was adjusted within the range of 1-20 mm, while the diameter was tuned from $100 \mathrm{~nm}$ to $2 \mu \mathrm{m}$ by changing the substrate temperature and the oxygen partial pressure during vapor deposition.

\subsubsection{Photoanodes with $\mathrm{ZnO}$ nanowires}

Law et al designed $\mathrm{ZnO}$ nanowire (NWs) arrays to increase the electron diffusion length and was applied as photoelectrode for the fabrication of DSSCs (Law, et al., 2005 \& Greene, et al., 
2006). The grown $\mathrm{ZnO}$ nanowires arrays films exhibited the relatively good resistivity values between the range of 0.3 to $2.0 \Omega \mathrm{cm}$ for the individual nanowires with an electron concentration of $1-5 \times 10^{18} \mathrm{~cm}^{3}$ and a mobility of $1-5 \mathrm{~cm}^{2} \mathrm{~V}-1 \mathrm{~s}^{-1}$. The overall conversion efficiencies of 1.2-1.5\% were obtained by DSSCs fabricated with $\mathrm{ZnO}$ nanowires arrays with short-circuit current densities of $5.3-5.85 \mathrm{~mA} / \mathrm{cm}^{2}$, open-circuit voltages of $0.610-0.710 \mathrm{~V}$, and fill factors of 0.36-0.38. Another group synthesized $\mathrm{ZnO}$ NWs by the use of ammonium hydroxide for changing the supersaturation degree of $\mathrm{Zn}$ precursors in solution process (Regan, et al., 1991). The length-to-diameter aspect ratio of the individual nanowires was easily controlled by changing the concentration of ammonium hydroxide. The fabricated DSSCs exhibited remarkably high conversion efficiency of $1.7 \%$ which was much higher than DSSC with ZnO nanorod arrays (Gao, et al., 2007). C. Y. Jiang et al reported the flexible DSSCs with a highly bendable ZnO NWs film on PET/ITO substrate which was prepared by a low-temperature hydrothermal growth at $85^{\circ} \mathrm{C}$ (Jiang, et al., 2008). The fabricated composite films obtained by immersing the ZnO NPs powder in a methanolic solution of $2 \%$ titanium isopropoxide and $0.02 \mathrm{M}$ acetic acid was treated with heat which favored the good attachment of NPs onto NWs surfaces (Jiang, et al., 2008). Here, the conversion efficiency of the fabricated DSSCs was achieved less as compared to DSSCs based on NPs.

\subsubsection{Photoanodes with ZnO nanorods}

A. J. Cheng et al synthesized aligned $\mathrm{ZnO}$ nanorods (NRs) on indium tin oxide (ITO) coated glass substrate via a thermal chemical vapor deposition (CVD) (Cheng, et al., 2008) at very high temperature which affected the crystalline properties of ZnO NRs. The rapid largescale synthesis of well-crystalline and good surface area of hexagonal-shaped ZnO NRs was carried out by A. Umar et al at very low temperature $\left(70^{\circ} \mathrm{C}\right)$ for the application of DSSCs (Umar, et al., 2009). A high overall light to electricity conversion efficiency of $1.86 \%$ with high fill factor (FF) of $74.4 \%$, high open-circuit voltage $\left(\mathrm{V}_{\mathrm{OC}}\right)$ of $0.73 \mathrm{~V}$ and short-circuit current (Jsc) of $3.41 \mathrm{~mA} / \mathrm{cm}^{2}$ was achieved by fabricated DSSCs. M. S. Akhtar et al reported the morphology of $\mathrm{ZnO}$ flowers through hydrothermal process using Zinc acetate, $\mathrm{NaOH}$ and ammonia as capping agent. The photoanode was prepared by spreading the $\mathrm{ZnO}$ paste on FTO substrate by doctor blade technique for the fabrication of DSSCs (Akhatr, et al., 2007). Unfortunately, the DSSC presented a very low conversion efficiency of $0.3 \%$ with high FF of 0.54 . The low performance might attribute to the low dye absorption on the surface of $\mathrm{ZnO}$ due to the less uniformity of the thin film with low surface to volume ratio. Furthermore, a flower like structures comprised with nanorods/nanowires can be assumed to deliver a larger surface area and a direct pathway for electron transport with the channels arisen from the branched to nanrods/nanowire backbone. Recently, hydrothermally grown $\mathrm{ZnO}$ nanoflower films accomplished improved overall conversion efficiency of $1.9 \%$ with high JSC of $5.5 \mathrm{~mA} \mathrm{~cm}^{2}$, and a fill factor of 0.53 (Jiang, et al., 2007) which is higher than nanorod arrays films based DSSC of the conversion efficiency $1.0 \%$, JsC $4.5 \mathrm{~mA} / \mathrm{cm}^{2}$, and FF 0.36 .

\subsubsection{Photoanodes with $\mathrm{ZnO}$ nanotubes}

L. Vayssiers et al grown the $\mathrm{ZnO}$ microtubes arrays by thermal decomposition of a $\mathrm{Zn}^{2+}$ amino complex at $90^{\circ} \mathrm{C}$ in a regular laboratory oven (Vayssieres, et al., 2001). The synthesized $\mathrm{ZnO}$ microtubes arrays possessed a high porosity and large surface area as compared to ZnO NWs arrays. A. B. F. Martinson et al fabricated the ZnO nanotubes (NTs) arrays by coating anodic aluminum oxide (AAO) membranes via atomic layer deposition 
(ALD) and constructed the DSSCs which showed a relatively low conversion efficiency of $1.6 \%$ due to the less roughness factor of commercial membranes (Martinson, et al., 2007). In continuity, Ameen et al reported the aligned ZnO NTs, grown at low temperature and applied as photoanode for the performances of DSSCs (Ameen, et al., 2011). The ZnO seeded FTO glass substrate supported the synthesis of highly densely aligned ZnO NTs whereas, non-seeded FTO substrates generated non-aligned ZnO NTs. The non-aligned ZnO NTs photoanode based fabricated DSSCs reported the low solar-to-electricity conversion efficiency of $\sim 0.78 \%$. However, DSSC fabricated with aligned ZnO NTs photoanode showed three times improved solar-to-electricity conversion efficiency than DSSC fabricated with non-aligned ZnO NTs. Fig. 19 shows the surface FESEM images of ZnO NTs deposited on non-seeded and ZnO seeded FTO substrates. Fig. 19 (a \& b) exhibits the highly densely aligned ZnO NTs, substantially grown on ZnO seeded FTO substrates. Importantly, the ZnO NTs possess a hexagonal hollow structure with average inner and outer diameter of $\sim 150 \mathrm{~nm}$ and $\sim 300 \mathrm{~nm}$, respectively, as shown in Fig. 19 (c \& d). However, non-seeded FTO substrates (Fig. 19 (e)) obtain the random and non-aligned morphology of NTs with the average diameter of $800 \mathrm{~nm}$. The high resolution image clearly displays the typical hexagonal hollow and round end of the NTs (Fig. 19 (f)). Fig. 20(a) of TEM image reveals hollow NT morphology with the outer and inner diameter of $\sim 250 \mathrm{~nm}$ and $\sim 100 \mathrm{~nm}$, respectively. SAED patterns (Fig. 20 (c)) exhibits a single crystal with a wurtzite hexagonal phase which is preferentially grown in the [0001] direction. It is further confirmed from the HRTEM image of the grown ZnO NTs, presented in Fig. 20(b). HRTEM image shows wellresolved lattice fringes of crystalline ZnO NTs with the inter-planar spacing of $\sim 0.52 \mathrm{~nm}$. Additionally, this value corresponds to the d-spacing of [0001] crystal planes of wurtzite $\mathrm{ZnO}$. Thus, the synthesized ZnO NTs is a single crystal and preferentially grown along the c-axis [0001].

The XRD peaks (Fig 21 (a)) of grown aligned ZnO NTs on the seeded substrates appear at the same position but with high intensity might due to high crystalline properties of aligned morphology of ZnO NTs. The UV-Vis spectra as shown in Fig 21 (b)) exhibit a single peak which indicates that the grown ZnO NTs do not contain impurities. Moreover, the aligned morphology of ZnO NTs attains high absorption, indicating the higher crystalline properties than non-aligned ZnO NTs.

The Raman spectra of non- aligned and aligned ZnO NTs is shown in Fig 22 (a). The grown $\mathrm{ZnO}$ NTs exhibits a strong Raman peak at $\sim 437 \mathrm{~cm}^{-1}$ corresponds to $\mathrm{E}_{2}$ mode of $\mathrm{ZnO}$ crystal and two small peaks at $\sim 330 \mathrm{~cm}^{-1}$ and $\sim 578 \mathrm{~cm}^{-1}$ are assigned to the second order Raman spectrum arising from zone-boundary phonons $3 \mathrm{E}_{2 \mathrm{H}}-\mathrm{E}_{2 \mathrm{~L}}$ for wurtzite hexagonal $\mathrm{ZnO}$ single crystals and $\mathrm{E}_{1}(\mathrm{LO})$ mode of $\mathrm{ZnO}$ associated with oxygen deficiency in $\mathrm{ZnO}$ nanomaterials respectively (Exarhas, et al., 1995). Compared to non-aligned ZnO NTs, the stronger $\mathrm{E}_{2}$ mode and much lower $\mathrm{E}_{1}$ (LO) mode indicates the presence of lower oxygen vacancy. The Raman active $\mathrm{E}_{2}$ mode with high intensity and narrower spectral width is generally ascribed to the better optical and crystalline properties of the materials (Serrano, et al., 2003) and thus, the grown aligned ZnO NTs results high crystallinity of ZnO crystals with less oxygen vacancies. Fig 22 (b) depicts the PL spectra of grown non-aligned and aligned ZnO NTs. An intensive sharp UV emission at $\sim 378 \mathrm{~nm}$ and a broader green emission at $\sim 581 \mathrm{~nm}$ are attributed to the free exciton emission from the wide band gap of ZnO NTs and the recombination of electrons in single occupied oxygen vacancies in $\mathrm{ZnO}$ nanomaterials (Vanheusden, et al., 1996). The high intensity and less broaden green emission indicates that 
the aligned $\mathrm{ZnO}$ NTs exhibits less oxygen vacancies and considerable stoichiometric phase structure formation. Thus, the PL spectra suggest that ZnO seeding on FTO substrates might improve surface-to-volume ratio and optical properties of ZnO NTs.

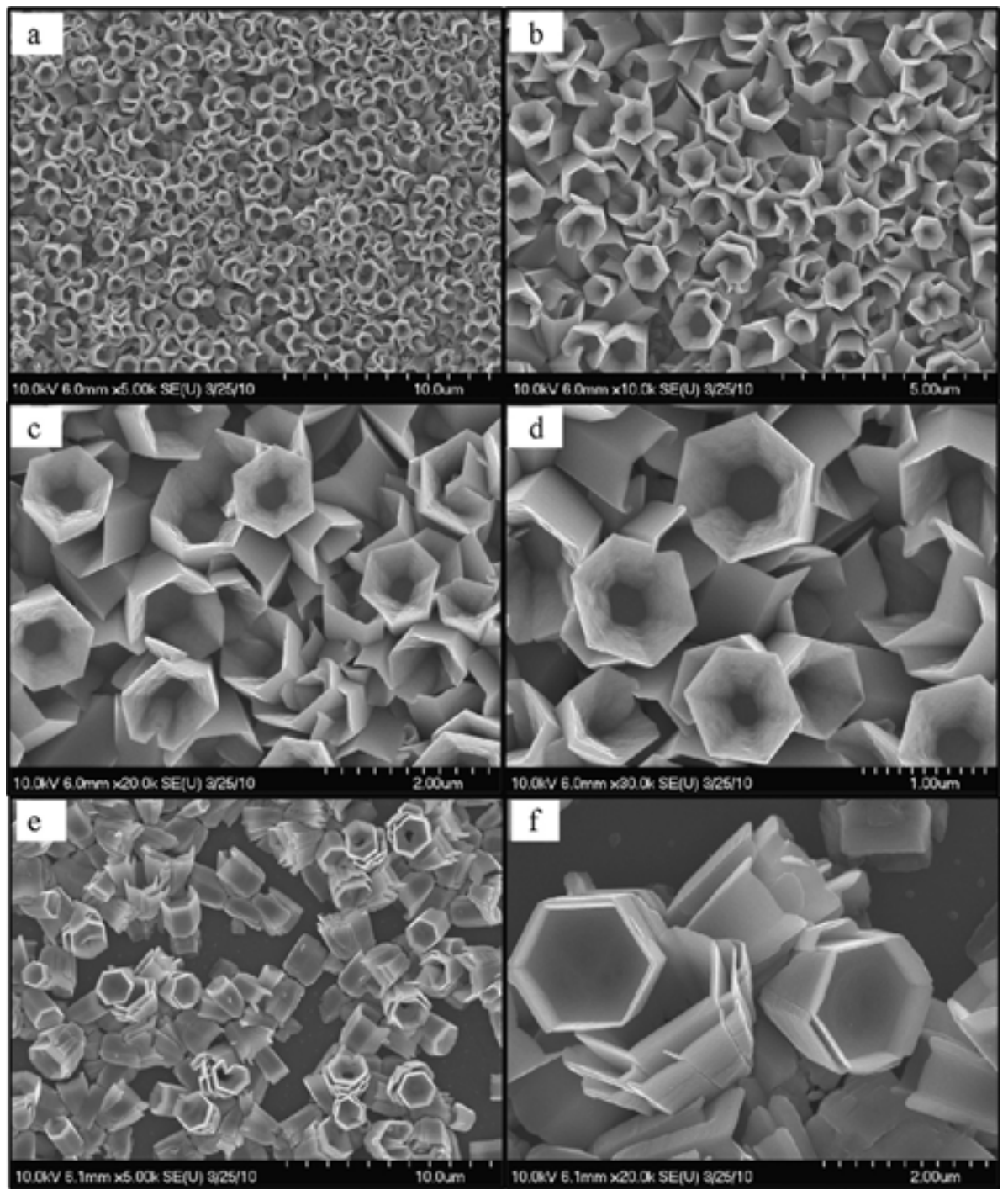

Fig. 19. FESEM images of aligned ZnO NTs (a) at low magnification and (b-d) at high magnification. (e) non-aligned ZnO NTs images at low magnification and (f) at high magnification. Reprinted with permission from [Ameen S. et al, 2011], Electrochim. Acta, 56 (2011) 1111. @ 2011 , Elsevier Ltd. 

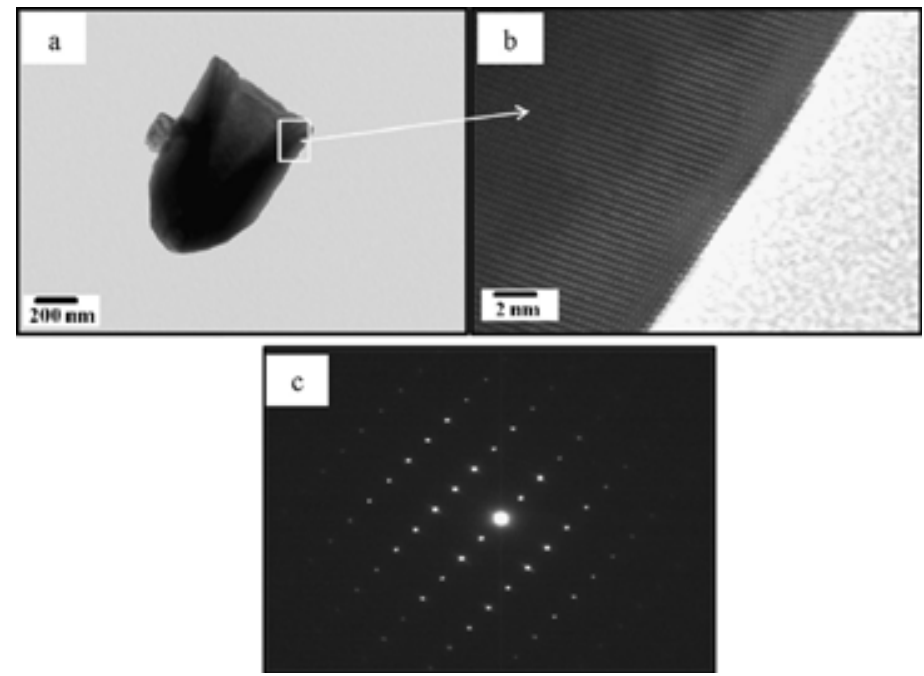

Fig. 20. (a) TEM, (b) HR-TEM and (c) corresponding SAED images of grown ZnO NTs. Reprinted with permission from [Ameen S. et al, 2011], Electrochim. Acta, 56 (2011) 1111. (c) 2011, Elsevier Ltd.
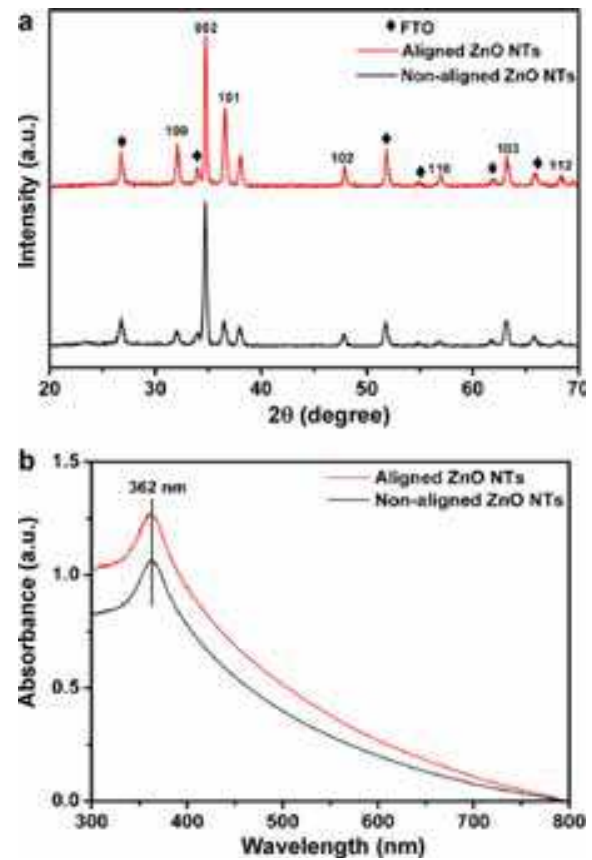

Fig. 21. (a) XRD pattern and (b) UV-Vis spectra of aligned and non-aligned ZnO NTs.

Reprinted with permission from [Ameen S. et al, 2011], Electrochim. Acta, 56 (2011) 1111. ( C) 2011, Elsevier Ltd. 

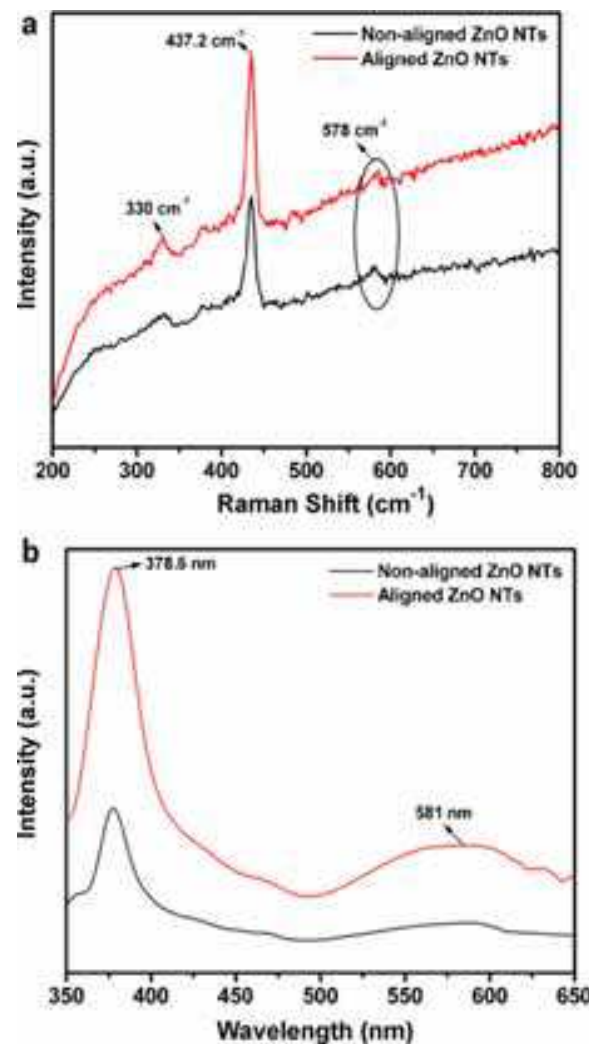

Fig. 22. (a) Raman spectra and (b) photoluminescence spectra of aligned and nonaligned ZnO NTs. Reprinted with permission from [Ameen S. et al, 2011], Electrochim. Acta, 56 (2011) 1111. (c) 2011, Elsevier Ltd.

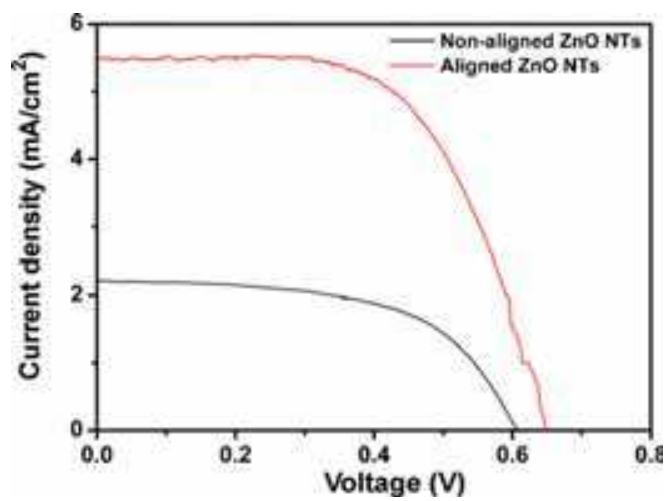

Fig. 23. J-V curve of the DSSCs fabricated with aligned and non-aligned ZnO NTs photoanode. Reprinted with permission from [Ameen S. et al, 2011], Electrochim. Acta, 56 (2011) 1111. @ 2011, Elsevier Ltd. 


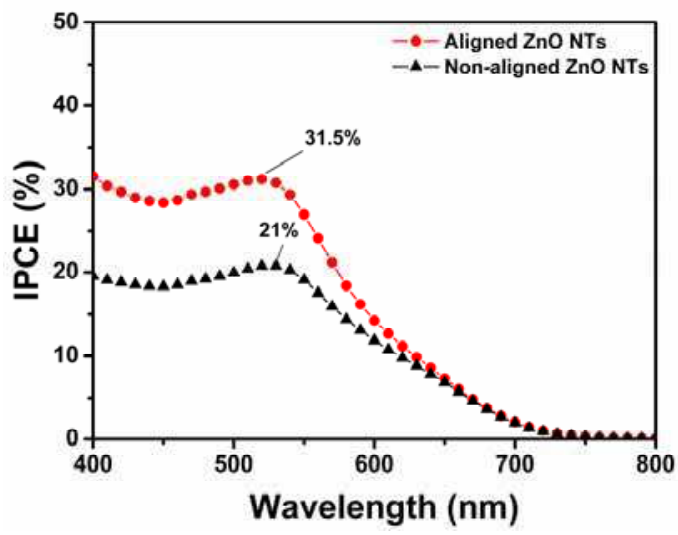

Fig. 24. IPCE curves of the DSSCs fabricated with aligned and non-aligned ZnO NTs photoanode. Reprinted with permission from [Ameen S. et al, 2011], Electrochim. Acta, 56 (2011) 1111. (c) 2011, Elsevier Ltd.

Fig 23 shows that DSSCs fabricated with aligned ZnO NTs photoanode achieve high solarto-electricity conversion efficiency of $2.2 \%$ with a high short circuit current (JSC) of 5.5 $\mathrm{mA} / \mathrm{cm}^{2}$, open circuit voltage $\left(\mathrm{V}_{\mathrm{OC}}\right)$ of $0.65 \mathrm{~V}$, and fill factor $(\mathrm{FF})$ of 0.61 . Compared with non-aligned ZnO NTs photoanode based DSSC, the aligned ZnO NTs photoanode has appreciably enhanced the conversion efficiency by three times with significantly improved JSC, $\mathrm{V}_{\mathrm{OC}}$ and FF. The DSSC fabricated with non-aligned ZnO NTs pho-to anode executes relatively low of $0.78 \%$ with JSC of $2.2 \mathrm{~mA} / \mathrm{cm}^{2}, \mathrm{~V}_{\mathrm{OC}}(0.60 \mathrm{~V})$ and FF of 0.57 . The enhanced photovoltaic performances and the improved $\mathrm{J}_{\mathrm{SC}}$ are mainly related to the highly dense morphology of aligned ZnO NTs and also, high dye absorption which leads to improved light harvesting efficiency. The aligned morphology might result from the sufficiently high surface area of ZnO NTs and thus, execute reasonably high charge collection and the transfer of electrons at the interface of ZnO NTs and electrolyte layer. While, low efficiency of non-aligned ZnO NTs might associate to low surface area of ZnO NTs and non-uniform surface which might result to low light harvesting efficiency and increases the recombination rate between the electrolyte and the FTO substrate. Ameen et al has reported that the performance of DSSCs with grown aligned ZnO NTs photoanode is significantly higher than the reported DSSCs with aligned $\mathrm{ZnO}$ nanorods, nanowires and nanotubes based photoanode (Pasquier, et al., 2006 \& Singh, et al., 2010). Importantly, the aligned ZnO NTs based DSSC achieves a maximum IPCE value of $\sim 31.5 \%$ at $\sim 520 \mathrm{~nm}$ as shown in Fig 24 . The considerably low IPCE $(\sim 21 \%)$ is obtained with non-aligned ZnO NTs photoanode based DSSC and thus, the aligned ZnO NTs photoanode presents approximately two times improved IPCE compared to non-aligned ZnO NTs photoanode. The enhancement in IPCE imputes the influence of highly ordered aligned ZnO NTs morphology with high surface area which might improve the light scattering capacities and provides the better interaction between the photons and the dye molecules (Tachibana, et al., 2002).

\section{Conclusions}

The chapter summarizes the synthesis of PANI through simple and novel polymerization techniques, the concept of doping, types of dopants and the application of PANI in 
heterostructure devices, diodes and DSSCs. Additionally, the recent surveys on various metal oxide nanomaterials nanomaterials have been thoroughly carried out in terms of their synthesis, morphology and applications in photovoltaic devices. The effective polymerization procedures for PANI particularly, electrophoretic and plasma enhanced deposition are the most promising techniques for optimizing the uniformity, penetration, thickness, electrical conductivity and form the uniform PANI thin films for the high performance and high quality of $\mathrm{p}-\mathrm{n}$ heterostructure devices and diodes. The choices of dopants are crucial to define the conductive, electrical properties and performances of heterostructure devices such as diodes and DSSCs. The review analyzes various organic/inorganic acids as efficient dopants to enhance the conducting properties of PANI, which confirm that the electronic and optical properties of PANI could be easily controlled and tailored by the oxidizing/reducing agents and acid/base doping during the polymerization procedures. In the second part, the unique and the versatile properties of metal oxides nanostructures especially $\mathrm{TiO}_{2}$ and $\mathrm{ZnO}$ show significant influences on the performances of electrical, electrochemical, and photovoltaic devices by delivering high surface to volume ratio for high absorption of dye molecules, which leads high light harvesting efficiency and increases the electron transfer as well as photocurrent density during the operation of DSSCs. Moreover, various sizes and shapes like nanorods, nanowires and nanotubes of metal oxides nanomaterials particularly $\mathrm{TiO}_{2}$ and $\mathrm{ZnO}$ have been reviewed evidently in terms of morphology and the photovoltaic properties of DSSCs such as $\mathrm{JSC}_{\mathrm{SC}} \mathrm{V}_{\mathrm{OC}}, \mathrm{FF}$ and conversion efficiency. Conclusively, the doping, and method of PANI deposition techniques improve the electrical conductivity and the electrocatalytic activity of the devices and exhibit the direct effect on the performances of DSSCs.

\section{References}

Grätzel, M., Solar Energy Conversion by Dye-Sensitized Photovoltaic Cells, Inorg. Chem., 44 (2005) 6841-6851.

Grätzel, M., Conversion of sunlight to electric power by nanocrystalline dye-sensitized solar cells, J. Photochem. Photobiol. A, 164 (2004) 1-14.

Frank, A. J., \& Kopidakis, N., J. V. D. Lagemaat, Electrons in nanostructured $\mathrm{TiO}_{2}$ solar cells: transport, recombination and photovoltaic properties, Coord., Chem. Rev., 248 (2004) 1165-1179.

Gratzel, M., Perspectives for Dye-sensitized Nanocrystalline Solar Cells, Prog. Photovolt. Res. Appl., 8 (2000) 171-185.

Huang, J., \& Kaner, R. B., The intrinsic nanofibrillar morphology of polyaniline, Chem. Commun., (2006) 367-376.

Zhang, D., \& Wang, Y., Synthesis and applications of one-dimensionalnano-structured polyaniline: An overview, Mater. Sci. Eng. B, 134 (2006) 9-19.

Wan, M., A Template-Free Method Towards Conducting Polymer Nanostructures, Adv. Mater., 20 (2008) 2926-2932.

Wan, M., Some Issues Related to Polyaniline Micro-/Nanostructures, Macromol. Rapid Commun., 30 (2009) 963-975.

Li, D., Huang, J., \& Kaner, R.B., Polyaniline Nanofibers: A Unique Polymer Nanostructure for Versatile Applications, Acc. Chem. Res., 42 (2009)135-145.

Stejskal J. \& Gilbert R. G., Polyaniline. Preparation of a Conducting Polymer, Pure Appl. Chem., 74 (2002) 857-867. 
Friend, R. H., Gymer, R.W., \& Holmes, A. B., Electroluminescence in conjugated polymers, Nature (London), 397 (1999) 121-128.

Park J. K. \& Kwon O-P., Enhanced electrical conductivity of polyaniline film by a low magnetic field, Synth. Met. 160 (2010) 728-731.

Gerard, M., Chaubey, A., \& Malhotra, B. D., Application of conducting polymers to biosensors, Biosensor Bioeleton., 17 (2002) 345-359.

Xia, L., Wei, Z., \& Wan, M., Conducting polymer nanostructures and their application in biosensors, J. Coll. Interf. Sci., 341 (2010) 1-11.

Smith, J. D. S., Intrinsically Electrically Conducting Polymers. Synthesis, Characterization and their Applications, Prog. Polym. Sci., 23 (1998) 57-79.

Wessling, B., From conductive polymers to organic metals, Chem. Innov., 31 (2001) 34-40.

Cho, Y. H., Cho, M.S., Choi, H. J., \& Jhon, M. S., Electrorheological characterization of polyaniline-coated poly(methyl methacrylate)suspensions, Colloid Polym. Sci., 280 (2002) 1062-1066.

Choi, H. J., Cho, M. S., Kim, J.W., Kim, C.A., \& Jhon, M. S., A yield stress scaling function for electrorheological fluids, Appl. Phys. Lett., 78 (2001) 3806-3809.

Ameen, S., Akhtar, M. S., \& Husain, M., Polyaniline and Its Nanocomposites: Synthesis, Processing, Electrical Properties and Applications, Sci. Adv. Mater., 2 (2010) 441-462.

Huang, J. X., Virji, S., Weiller, B. H., \& Kaner, R.B., Polyaniline Nanofibers: Facile Synthesis and Chemical Sensors, J. Am. Chem. Soc., 125 (2003) 314-315.

Virji, S., Huang, J. X., Kaner, R. B., \& Weiller, B. H., Polyaniline Nanofiber Gas Sensors: Examination of Response Mechanisms, Nano Lett., 4 (2004) 491-496.

King, R. C. Y., \& Rousse, 1. F., Morphological and electrical characteristics of polyaniline nanifibers, Synth. Met., 153 (2005) 337-340.

Huang, J. X., \& Kaner, R. B., A General Chemical Route to Polyaniline Nanofibers, J. Am. Chem. Soc., 126 (2004) 851-855.

Jing, X. L., Wang, Y.Y., Wu, D., She, L., \& Guo, Y., Polyaniline Nanofibers Prepared with Ultrasonic Irradiation, J. Polym. Sci., Part A: Polym. Chem., 44 (2006) 1014-1019.

Jing, X. L., Wang, Y. Y., Wu, D., \& Qiang, J.P., Sonochemical synthesis of polyaniline nanofibers, Ultrason. Sonochem. 14 (2007) 75-80.

Dhaoui, W., Zarrouk, H., \& Pron, A., Spectroscopic properties of thin layers of sulfamic acid-doped polyaniline and their application to reagentless determination of nitrite, Synth. Metals, 157 (2007) 564-569.

Dhaoui, W., Bouzitoun, M., Zarrouk, H., Ouada, H. B., \& Pron, A., Electrochemical sensor for nitrite determination based on thin films of sulfamic acid doped polyaniline deposited on $\mathrm{Si} / \mathrm{SiO}_{2}$ structures in electrolyte/insulator/semiconductor (E.I.S.) configuration, Synth. Metals, 158 (2008) 722-726.

Ameen, S., Ali, V., Zulfequar, M., Haq, M. M., \& Husain, M., Electrical conductivity and dielectric properties of sulfamic acid doped polyaniline, Curr. Appl. Phys., 7 (2007) 215219.

Ameen, S., Akhtar, M. S., Kim, Y. S., Yang, O. B., \& Shin, H. S., Sulfamic Acid-Doped Polyaniline Nanofibers Thin Film-Based Counter Electrode: Application in Dye-Sensitized Solar Cells, J. Phys. Chem. C, 114 (2010) 4760-4764.

Ameen, S., Ali, V., Zulfequar, M., Haq, M. M., \& Husain, M., Preparation and measurements of electrical and spectroscopic properties of sodium thiosulphate doped polyaniline, Curr. Appl. Phys., 9 (2009) 478-483. 
Ameen, S., Ali, V., Zulfequar, M., Haq, M. M., \& Husain, M., Photoluminescence, FTIR, and Electrical Characterization of Samarium (III) Chloride-Doped Polyaniline, J. Appl. Polym. Sci., 112 (2009) 2315-2319.

Ameen, S., Ali, V., Zulfequar, M., Haq, M. M., \& Husain, M., Preparation and measurements of electrical and spectroscopic properties of praseodymium (III) chloride-doped polyaniline, Physica E, 40 (2008) 2805-2809.

Ameen, S., Ali, V., Zulfequar, M. Haq, M. M., \& Husain, M., DC Conductivity and Spectroscopic Characterization of Binary Dopant $\left(\mathrm{ZrO}_{2} / \mathrm{AgI}\right)$-Doped Polyaniline, J. Polym. Sci.: Part B: Polym. Phys., 45 (2007) 2682-2687.

Wang, S., Tan, Z., Li, Y., Sun, L., \& Zhang, T., Synthesis, characterization and thermal analysis of polyaniline $/ \mathrm{ZrO}_{2}$ composites, Thermochim. Acta, 441 (2006) 191-194.

Ameen, S., Lakshmi, G. B. V. S., \& Husain, M., Synthesis and characterization of polyaniline prepared with the dopant mixture of $\left(\mathrm{ZrO}_{2} / \mathrm{PbI}_{2}\right)$, J. Phys. D: Appl. Phys. 42 (2009) 105104-105109.

Ameen, S., Akhtar, M. S., Ansari, S. G., Yang, O. B., \& Shin, H. S., Electrophoretically deposited polyaniline/ZnO nanoparticles for $p$ - $n$ heterostructure diodes, Superlatt. Microstr., 46 (2009) 872-880.

Ameen, S., Akhtar, M. S., Kim, Y.S., Yang, O. B., \& Shin, H. S., Diode Behavior of Electrophoretically Deposited Polyaniline on TiO2 Nanoparticulate Thin Film Electrode, J. Nanosci. Nanotech., 11(2011) 1559-1564.

Somani, P. R., Marimuthu, R., Mulik, U. P., Sainkar, S. R., \& Amalnerkar, D. P., High piezoresistivity and its origin in conducting polyanilinerTiO $\mathrm{O}_{2}$ Composites, Synth. Met., 106 (1999) 45-52.

Niu, Z., Yang, Z., Hu, Z., Lu, Y., \& Han, C. C., Polyaniline-Silica Composite Conductive Capsules and Hollow Spheres, Adv. Funct. Mater., 13 (2003) 949-954.

Ameen, S., Ansari, S. G., Song, M., Kim, Y. S., \& Shin, H. S., Fabrication of polyaniline/TiO ${ }_{2}$ heterojunction structure using plasma enhanced polymerization technique, Superlatt. Microstruc. 46 (2009) 745-751.

Ameen, S., Akhtar, M. S., Kim, Y. S., Yang, O. B., \& Shin, H. S., Electrical and Structural Characterization of Plasma Polymerized Polyaniline/TiO $\mathrm{T}_{2}$ Heterostructure Diode: A Comparative Study of Single and Bilayer $\mathrm{TiO}_{2}$ Thin Film Electrode, J. Nanosci. Nanotech. 11 (2011) 3306-3313.

Dhawale, D. S., Alunkhe, R. R. S., Patil, U. M., Gurav, K. V., More, A. M., \& Lokhande, C. D., Room temperature liquefied petroleum gas (LPG) sensor based on p-polyaniline $/ n-\mathrm{TiO}_{2}$ heterojunction, Sens. Actua. B, 134 (2008) 988-992.

Nadarajah, A., Word, R. C., Meiss, J.,\& Konenkamp, R., Flexible Inorganic Nanowire LightEmitting Diode, Nano Lett., 8 (2008) 534-537.

Maeng, J., Jo, M., Kang, S. J., Kwon, M. K., Jo, G., Kim, T. W., Seo, J., Hwang, H., Kim D. Y.,\& Park S. J., T. Lee. Transient reverse current phenomenon in a $p$ - $n$ heterojunction comprised of poly (3,4-ethylene-dioxythiophene):poly(styrene-sulfonate) and $\mathrm{ZnO}$ nanowall, Appl. Phys. Lett., 93 (2008) 123109-123111.

Thompson, B. C., \& Frechet, J. M. J., Polymer-Fullerene Composite Solar Cells, Angew. Chem.Int. Ed., 47(2008) 58-77.

Gunes, S., Neugebauer, H., \& Sariciftci, N. S., Conjugated Polymer-Based Organic Solar Cells, Chem. Rev., 107(2007)1324-1338.

Bundgaard, E., \& Krebs, F. C., Low band gap polymers for organic photovoltaics, Sol. Energy Mater. Sol. Cells, 91(2007) 954-985. 
Shaw, P. E., Ruseckas, A., \& Samuel, I. D. W., Exciton Diffusion Measurements in Poly(3hexylthiophene), Adv. Mater., 20 (2008) 3516-3520.

Sirringhaus, H., Brown, P. J., Friend, R. H., Nielsen, M. M., Bechgaard, K., Langeveld V. B. M. W., Spiering, A. J. H., Janssen, R. A. J., Meijer, E. W., Herwig, P., \& Leeuw, D. M. D., Two-dimensional charge transport in self-organized, high-mobility conjugated polymers, Nature, 401(1999) 685-688.

Waldauf, C., Morana, M., Denk, P., Schilinsky, P., Coakley, K., Choulis, S. A., \& Brabec, C. J., Highly efficient inverted organic photovoltaics using solution based titanium oxide as electron selective contact, Appl. Phys. Lett., 89 (2006) 233517-233519.

Steim, R., Kogler, F. R., \& Brabec, C. J., Interface materials for organic solar cells, J. Mater. Chem., 20 (2010) 2499-2512.

Steim, R., Choulis, S. A., Schilinsky, P., \& Brabec, C. J., Interface modification for highly efficient organic photovoltaics, Appl. Phys. Lett., 92 (2008) 093303-093305.

Ameri, T., Dennler, G., Lungenschmied, C., \& Brabec, C. J., Organic tandem solar cells: A review, Ener. Environ. Sci., 2 (2009) 347-363.

Lee Y. J., Ruby, D. S., Peters, D.W., McKenzie, B. B., \& Hsu, J. W. P., ZnO Nanostructures as Efficient Antireflection Layers in Solar Cells, Nano Lett., 8 (2008) 1501-1505.

Cantu, M. L., IddikiM, K. S, Rojas, D. M., Amade, R., \& Pech, N. I. G., Nb-TiO2/polymer hybrid solar cells with photovoltaic response under inert atmosphere conditions, Sol. Energy Mater. Sol. Cells, 94 (2010)1227-1234.

Cantu, M. L., Norrman, K., Andreasen, J.W., \& Krebs, F.C., Oxygen Release and Exchange in Niobium Oxide MEHPPV Hybrid Solar Cells, Chem. Mater., 18 (2006) 5684-5690.

Cantu, M. L., Norrman, K., Andreasen, J.W., Pastor, N. C., \& Krebs, F.C., Detrimental Effect of Inert Atmospheres on Hybrid Solar Cells Based on Semiconductor Oxides, J. Electrochem. Soc., 154 (2007) B508.

Cantu, M. L., \& Krebs, F.C., Hybrid solar cells based on MEH-PPV and thin film semiconductor oxides $\left(\mathrm{TiO}_{2}, \mathrm{Nb}_{2} \mathrm{O}_{5}, \mathrm{ZnO}, \mathrm{CeO}_{2}\right.$ and $\left.\mathrm{CeO}_{2}-\mathrm{TiO}_{2}\right)$ : Performance improvement during longtime irradiation, Sol. Energy Mater. Sol. Cells, 90 (2006) 2076-2086.

Valls, I. G., \& Cantu, M. L., Dye sensitized solar cells based on vertically-aligned ZnO nanorods: effect of UV light on power conversion efficiency and lifetime, Ener. Environ. Sci., 3 (2010) 789-795.

Valls, I. G., \& Cantu, M. L., Vertically-aligned nanostructures of $\mathrm{ZnO}$ for excitonic solar cells: a review, Ener. Environ. Sci., 2 (2009) 19-25.

Arici, E., Meissner, D., Schaffler, F., \& Sariciftci, N.S., Core/shell nanomaterials in photovoltaics, Int. J. Photoenergy, 5 (2003) 199-208.

Sariciftci, N.S., Smilowitz, L., Heeger, A. J., \& Wudl, F., Photoinduced Electron Transfer from a Conducting Polymer to Buckminsterfullerene, Science, 258 (1992) 1474-1476.

Yu, G., Gao, J., Hummelen, J.C., Wudl, F., \& Heeger, A.J., Polymer Photovoltaic Cells: Enhanced Efficiencies via a Network of Internal Donor-Acceptor Heterojunctions, Science, 270 (1995) 1789-1791.

Ameen, S., Akhtar, M. S., Kim, G.S., Kim, Y. S., Yang, O. B., \& Shin, H. S., Plasma-enhanced polymerized aniline $/ \mathrm{TiO}_{2}$ dye-sensitized solar cells, J. Alloys Compd., 487 (2009) 382386.

Saito, Y., Kitamura, T., Wada, Y., \& Yanagida, S., Application of Poly (3,4ethylenedioxythiophene) to Counter Electrode in Dye-Sensitized Solar Cells, Chem. Lett. 31 (2002) 1060-1063., Y. Saito, W. Kubo, T. Kitamura, Y. Wada, S. Yanagida, $\mathrm{I}^{-} / \mathrm{I}_{3}{ }^{-}$ redox reaction behavior on poly(3,4-ethylenedioxythiophene) counter electrode in dyesensitized solar cells, J. Photochem. Photobiol. A. Chem. 164 (2004) 153-157. 
Li, Q., Wu, J., Tang, Q., Lan, Z., Li, P., Lin, J., \& Fan, L., Application of microporous polyaniline counter electrode for dye-sensitized solar cells, Electrochem. Commun. 10 (2008) 12991302.

Wu, J., Li, Q., Fan, L., Lan, Z., Li, P., Lin, J., \& Hao, S., High-performance polypyrrole nanoparticles counter electrode for dye-sensitized solar cells, J. Power Sour. 181 (2008) 172-176.

Lee, K. M., Chen, P. Y., Hsu, C. Y., Huang, J. H., Ho, W. H., Chen, H. C., \& Ho, K. C., A highperformance counter electrode based on poly(3,4-alkylenedioxythiophene) for dye-sensitized solar cells, J. Power Sour. 188 (2009) 313-318.

Zhang, J., Hreid, T., Li, X., Guo, W., Wang, L., Shi, X., Su, H., \& Yuan, Z., Nanostructured polyaniline counter electrode for dye-sensitised solar cells: Fabrication and investigation of its electrochemical formation mechanism, Electrochim. Acta, 55 (2010) 3664-3668.

Baxtera, J. B., \& Aydil, E. S., Dye-sensitized solar cells based on semiconductor morphologies with $\mathrm{ZnO}$ nanowires, Sol. Energy Mater. Sol. Cells, 90 (2006) 607-622.

Ito, S., Murakami, T. N., Comte, P., Liska, P., Grätzel, C., \& Nazeeruddin, M. K., Fabrication of thin film dye sensitized solar cells with solar to electric power conversion efficiency over 10\%, Thin Solid Films, 14 (2008) 4613-4619.

Law, M., Greene, L. E., Johnson, J.C., Saykally, R., \& Yang, P.D., Nanowire dye-sensitized solar cells, Nat. Mater., 6 (2005) 455-459.

Feng, X. J, Shankar, K., Varghese, O. K., Paulose, M., Latempa, T. J., \& Grimes, C. A., Vertically Aligned Single Crystal $\mathrm{TiO}_{2}$ Nanowire Arrays Grown Directly on Transparent Conducting Oxide Coated Glass: Synthesis Details and Applications, Nano Lett., 11(2008)3781-3786.

Macak, J. M., Tsuchiya, H., \& Schmuki, P., High-Aspect-Ratio $\mathrm{TiO}_{2}$ Nanotubes by Anodization of Titanium, Angew. Chem. Int Ed, 14 (2005) 2100-2102.

Mor, G. K., Shankar, K., Paulose, M., Varghese, O. K., \& Grimes, C. A., Enhanced Photocleavage of Water Using Titania Nanotube Arrays, Nano Lett., 1 (2005) 191-195.

Zhang, D. S., Yoshida, T., \& Minoura, H., Low-Temperature Fabrication of Efficient Porous Titania Photoelectrodes by Hydrothermal Crystallization at the Solid/Gas Interface, Adv Mater., 10 (2003) 814-817.

Wang, H., Liu, Y., Li, M., Huang, H., Zhong, M.Y., \& Shen, H., Hydrothermal growth of largescale macroporous $\mathrm{TiO}_{2}$ nanowires and its application in $3 \mathrm{D}$ dye-sensitized solar cells, Appl. Phys. A, 97 (2009) 25-29.

Ren, X., Gershon, T., Iza, D. C, Rojas, D. M., Musselman, K., \& Driscoll, J. L. M., The selective fabrication of large-area highly ordered $\mathrm{TiO}_{2}$ nanorod and nanotube arrays on conductive transparent substrates via sol-gel electrophoresis, Nanotechnology, 36 (2009) 365604-9.

Tan, L. K., Chong, M. A. S., \& Gao, H., Free-Standing Porous Anodic Alumina Templates for Atomic Layer Deposition of Highly Ordered $\mathrm{TiO}_{2}$ Nanotube Arrays on Various Substrates, J. Phys. Chem. C, 112 (2008) 69-73.

Tsai, T.Y., \& Lu, S.Y., A novel way of improving light harvesting in dye-sensitized solar cells Electrodeposition of titania, Electrochem. Commun., 11 (2009) 2180-2183.

Chen, Q.W., \& Xu, D.S., Large-Scale, Noncurling, and Free-Standing Crystallized $\mathrm{TiO}_{2}$ Nanotube Arrays for Dye-Sensitized Solar Cells, J. Phys. Chem. C, 113 (2009) 6310-6314.

Kang, T. S., Smith, A. P., Taylor, B. E., \& Durstock, M. F., Fabrication of highly-ordered $\mathrm{TiO}_{2}$ nanotube arrays and their use in dye-sensitized solar cells, Nano. Lett., 9 (2009) 601-606.

Regan, B. O., \& Graetzel, M., A low-cost, high-efficiency solar cell based on dye-sensitized colloidal $\mathrm{TiO}_{2}$ films, Nature, 353 (1991) 737-740.

Duffie, J., \& Beckman, W., Solar Engineering of Thermal Processes. Wiley: U.S.A., 1991 
Graetzel, M., Photoelectrochemical cells, Nature, 414 (2001) 338-344.

Zwilling, V., Aucouturier, M., \& Ceretti, E. D., Anodic oxidation of titanium and TA6V alloy in chromic media. An electrochemical approach, Electrochem. Acta, 45 (1999) 921-929.

Gong, D., Grimes, C. A., Varghese, O. K., Hu, W., Singh, R. S., Chen, Z., \& Dickey E.C., Titanium oxide nanotube arrays prepared by anodic oxidation, J. Mater. Res., 16 (2001) 3331-3334.

Guo, Y. G., Hu, J. S., Liang, H. P., Wan, L. J., \& Bai, C.L., TiO2-Based Composite Nanotube Arrays Prepared via Layer-by-Layer Assembly, Adv. Funct. Mater., 15 (2005) 196.

Martin, C. R., Nanomaterials: A Membrane-Based Synthetic Approach, Science, 266 (1994) 19611966.

Limmer, S. J., Seraji, S., Wu, Y., Chou, T. P., Nguyen, C., \& Cao, G. Z., Template-Based Growth of Various Oxide Nanorods by Sol-Gel Electrophoresis, Adv. Funct. Mater., 12 (2002) 5964.

Lakshmi, B. B., Dorhout, P. K., \& Martin, C. R., Sol-Gel Template Synthesis of Semiconductor Nanostructures, Chem. Mater., 9 (1997) 857-862.

Park, J. H., Lee, T.W., \& Kang, M.G., Growth, detachment and transfer of highly-ordered $\mathrm{TiO}_{2}$ nanotube arrays: use in dye-sensitized solar cells, Chem. Commun., (2008) 2867-2869.

Jiu, J., Isoda, S., Wang, F., \& Adachi, M., Dye-Sensitized Solar Cells Based on a Single-Crystalline TiO2 Nanorod Film, J. Phys. Chem. B, 110 (2006) 2087-2092.

Liu, B., \& Aydil, E. S., Growth of Oriented Single-Crystalline Rutile $\mathrm{TiO}_{2}$ Nanorods on Transparent Conducting Substrates for Dye-Sensitized Solar Cells, J. Am. Chem. Soc., 131(2009) 3985-3990.

Oh, J. K., Lee, J. K., Kim, H.S., Han, S. B., \& Park, K.W., $\mathrm{TiO}_{2}$ Branched Nanostructure Electrodes Synthesized by Seeding Method for Dye-Sensitized Solar Cells, Chem. Mater., 22 (2010) 1114-1118.

Spanhel, L., \& Anderson, M. A., Semiconductor clusters in the sol-gel process: quantized aggregation, gelation, and crystal growth in concentrated zinc oxide colloids, J. Am. Chem. Soc., 113(1991) 2826-2833.

Keis, K., Vayssieres, L., Rensmo, H., Lindquist, S. E., \& Hagfeldt, A., Photoelectrochemical properties of nano-to microstructured $\mathrm{ZnO}$ electrodes, J. Electrochem. Soc., 148 (2001) A149-153.

Redmond, G., Fitzmaurice, D., \& Graetzel, M., Visible Light Sensitization by cisBis(thiocyanato)bis(2,2'-bipyridyl-4,4'-dicarboxylato)ruthenium (II) of a Transparent Nanocrystalline ZnO Film Prepared by Sol-Gel Techniques, Chem. Mater., 6(1994) 686691.

Rani, S., Suri, P., Shishodia, P. K., \& Mehra, R. M., Synthesis of nanocrystalline ZnO powder via sol-gel route for dye-sensitized solar cells, Sol. Energ. Mat. Sol. C, 92 (2008) 1639-1645.

Zeng, L. Y., Dai, S. Y., Xu, W. W., \& Wang, K. J., Dye-Sensitized Solar Cells Based on ZnO Films, Plasma Sci. Tech., 8 (2006) 172-176.

Keis, K., Bauer, C., Boschloo, G., Hagfeldt, A., Westermark, K., Rensmo, H., \& Siegbahn, H., Nanostructured $\mathrm{ZnO}$ electrodes for dye-sensitized solar cell applications, J. Photochem. Photobiol. A: Chem., 148(2002) 57-64.

Keis, K., Magnusson, E., Lindstrom, H., Lindquist, S. E., \& Hagfeldt, A., A $5 \%$ efficient photoelectrochemical solar cell based on nanostructured $\mathrm{ZnO}$ electrodes, Sol. Energ. Mat. Sol. Cells, 73(2002) 51-58.

Suliman, A. E., Tang, Y. W., \& Xu, L., Preparation of $\mathrm{ZnO}$ nanoparticles and nanosheets and their application to dye-sensitized solar cells, Sol. Energ. Mat. Sol. Cells, 91(2007) 1658-1662. 
Akhtar, M. S., Khan, M. A., Jeon, M. S., \& Yang, O. B., Controlled synthesis of various ZnO nanostructured materials by capping agents-assisted hydrothermal method for dyesensitized solar cells, Electrochim. Acta, 53(2008) 7869-7874.

Lin, C. F., Lin, H., Li, J. B., \& Li, X., Electrodeposition preparation of $\mathrm{ZnO}$ nanobelt array films and application to dye-sensitized solar cells, J. Alloys Compd., 462 (2008)175-180

Hsu, Y. F., Xi, Y. Y., Yip, C. T., Djurisic, A. B., \& Chan, W. K., Dye-sensitized solar cells using ZnO tetrapods, J. Appl. Phys., 103(2008) 083114-083117.

Chen, W., Zhang, H. F., Hsing, I. M., \& Yang, S. H., A new photoanode architecture of dye sensitized solar cell based on $\mathrm{ZnO}$ nanotetrapods with no need for calcination, Electrochem. Commun., 11(2009) 1057-1060.

Law, M., Greene, L. E., Johnson, J. C., Saykally, R., \& Yang, P. D., Nanowire dye-sensitized solar cells, Nat. Mater., 4 (2005) 455-459.

Greene, L. E., Yuhas, B. D., Law, M., Zitoun, D., \& Yang, P. D., Solution-Grown Zinc Oxide Nanowires, Inorg. Chem., 45(2006) 7535-7543.

Gao, Y. F., Nagai, M., Chang, T. C., \& Shyue, J. J., Solution-Derived ZnO Nanowire Array Film as Photoelectrode in Dye-Sensitized Solar Cells, Cryst. Grow. Des. 7 (2007) 2467-2471.

Jiang, C. Y., Sun, X. W., Tan, K. W., Lo, G. Q., Kyaw, A. K. K., \& Kwong, D. L., Highbendability flexible dye-sensitized solar cell with a nanoparticle-modified $\mathrm{ZnO}$-nanowire electrode, Appl. Phy. Lett., 92(2008) 143101-143103.

Cheng, A. J., Tzeng, Y., Zhou, Y., Park, M., Wu, T.H., Shannon, C., Wang, D., \& Lee, W., Thermal chemical vapor deposition growth of zinc oxide nanostructures for dye-sensitized solar cell fabrication, Appl. Phys. Lett., 92 (2008) 092113-092115

Umar, A., Al-Hajry, A., Hahn, Y.B., \& Kim, D.H., Rapid synthesis and dye-sensitized solar cell applications of hexagonal-shaped $\mathrm{ZnO}$ nanorods, Electrochim. Acta, 54 (2009) 5358-5362.

Jiang, C. Y., Sun, X. W., Lo, G. Q., Kwong, D. L., \& Wang, J. X., Improved dye-sensitized solar cells with a ZnO-nanoflower photoanode, Appl. Phy. Lett. 2007, 90, 263501-263503.

Vayssieres, L., Keis, K., Hagfeldt, A., \& Lindquist, S. E., Three-Dimensional Array of Highly Oriented Crystalline ZnO Microtubes, Chem. Mater., 13(2001) 4395-4398.

Martinson, A. B. F., Elam, J. W., Hupp, J. T., \& Pellin, M. J., ZnO Nanotube Based DyeSensitized Solar Cells, Nano Lett., 7(2007) 2183-2187.

Ameen, S., Akhtar, M. S., Kim, Y.S., Yang, O. B., \& Shin, H. S., Influence of seed layer treatment on low temperature grown $\mathrm{ZnO}$ nanotubes: Performances in dye sensitized solar cells, Electrochim. Acta, 56 (2011) 1111-1116.

Exarhos, G. J., \& Harma, S. K. S, Influence of processing variables on the structure and properties of ZnO films, Thin Solid Films, 270 (1995) 27-32.

Serrano, J., Manjon, F. J., Romero, A. H., Widulle, F., Lauck, R., \& Cardona, M., Dispersive Phonon Linewidths: The E 2 Phonons of ZnO, Phys. Rev. Lett., 90 (2003) 0555100555113.

Vanheusden, K., Warren, W. L., Seager, C. H., Tallant, D. R., Voigt, J. A., \& Gnade, B.E., Mechanisms behind green photoluminescence in $\mathrm{ZnO}$ phosphor powders, J. Appl. Phys., 79 (1996) 7983-7990.

Pasquier, A. D., Chen, H., \& Lu, Y., Dye sensitized solar cells using well-aligned zinc oxide nanotip arrays, Appl. Phys. Lett., 89 (2006) 253513-253515.

Singh, D. P., Synthesis and Growth of ZnO Nanowires, Sci. Adv. Mater., 2 (2010) 245-271.

Tachibana, Y., Hara, K., Sayama, K., \& Arakawa, H., Quantitative Analysis of Light-Harvesting Efficiency and Electron-Transfer Yield in Ruthenium-Dye-Sensitized Nanocrystalline $\mathrm{TiO}_{2}$ Solar Cells, Chem. Mater., 14 (2002) 2527-2535. 


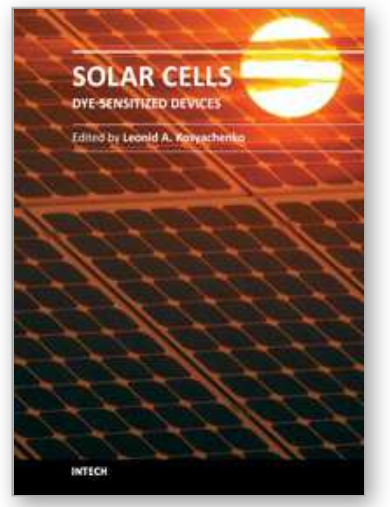

\author{
Solar Cells - Dye-Sensitized Devices \\ Edited by Prof. Leonid A. Kosyachenko
}

ISBN 978-953-307-735-2

Hard cover, 492 pages

Publisher InTech

Published online 09, November, 2011

Published in print edition November, 2011

The second book of the four-volume edition of "Solar cells" is devoted to dye-sensitized solar cells (DSSCs), which are considered to be extremely promising because they are made of low-cost materials with simple inexpensive manufacturing procedures and can be engineered into flexible sheets. DSSCs are emerged as a truly new class of energy conversion devices, which are representatives of the third generation solar technology. Mechanism of conversion of solar energy into electricity in these devices is quite peculiar. The achieved energy conversion efficiency in DSSCs is low, however, it has improved quickly in the last years. It is believed that DSSCs are still at the start of their development stage and will take a worthy place in the largescale production for the future.

\title{
How to reference
}

In order to correctly reference this scholarly work, feel free to copy and paste the following:

Sadia Ameen, M. Shaheer Akhtar, Young Soon Kim and Hyung-Shik Shin (2011). Fabrication, Doping and Characterization of Polyaniline and Metal Oxides: Dye Sensitized Solar Cells, Solar Cells - Dye-Sensitized Devices, Prof. Leonid A. Kosyachenko (Ed.), ISBN: 978-953-307-735-2, InTech, Available from: http://www.intechopen.com/books/solar-cells-dye-sensitized-devices/fabrication-doping-and-characterizationof-polyaniline-and-metal-oxides-dye-sensitized-solar-cells

\section{INTECH}

open science | open minds

\author{
InTech Europe \\ University Campus STeP Ri \\ Slavka Krautzeka 83/A \\ 51000 Rijeka, Croatia \\ Phone: +385 (51) 770447 \\ Fax: +385 (51) 686166 \\ www.intechopen.com
}

\author{
InTech China \\ Unit 405, Office Block, Hotel Equatorial Shanghai \\ No.65, Yan An Road (West), Shanghai, 200040, China \\ 中国上海市延安西路65号上海国际贵都大饭店办公楼 405 单元 \\ Phone: +86-21-62489820 \\ Fax: +86-21-62489821
}


(C) 2011 The Author(s). Licensee IntechOpen. This is an open access article distributed under the terms of the Creative Commons Attribution 3.0 License, which permits unrestricted use, distribution, and reproduction in any medium, provided the original work is properly cited. 